\title{
Influence of Internal Variability and Global Warming on Multidecadal Changes in Regional Drought Severity over the Continental United States ${ }^{\mathscr{O}}$
}

\author{
TUSHAR APURV AND XIMING CAI \\ VenTe Chow Hydrosystems Laboratory, Department of Civil and Environmental Engineering, \\ University of Illinois at Urbana-Champaign, Urbana, Illinois \\ XING YUAN \\ School of Hydrology and Water Resources, Nanjing University of Information Science \\ and Technology, Nanjing, Jiangsu, China
}

(Manuscript received 14 August 2018, in final form 30 December 2018)

\begin{abstract}
Meteorological droughts in the continental United States (CONUS) are known to oscillate at the multidecadal time scale in response to the sea surface temperatures (SST) variability over the Pacific Ocean and the North Atlantic Ocean. While previous studies have focused on understanding the influence of SST oscillations on drought frequency over the CONUS, this information has not been integrated with global warming for future drought risk assessment at the decadal scale. In this study, we use the support vector machines (SVMs) to handle correlation between input variables for quantifying the influence of internal variability [Atlantic multidecadal oscillation (AMO) and Pacific decadal oscillation (PDO)] and global warming on the decadal changes in the severity of seasonal droughts over the CONUS during 1901-2015. The regional drivers of drought severity identified using SVMs are used for the assessment of decadal drought risk in the near future. We find internal variability as the dominant driver of decadal changes in drought severity in the southern and central Great Plains and global warming as the dominant driver for the southeastern and southwestern United States. In the southern Plains, the existing pattern of increasing drought severity is likely to persist in the near future if AMO and PDO remain in their positive and negative phases, respectively, while global warming is likely to contribute to increasing drought severity in the Southeast and Southwest. This study suggests an emerging role of global warming in drought risk over the southern states, where near-term climate change adaptation is necessary.
\end{abstract}

\section{Introduction}

Droughts are one of the costliest natural disasters, as they can last for multiple seasons or years and can cause widespread impacts on water resources, economy, environment, and society (WMO 2006). Understanding of the spatial distribution and temporal change patterns of droughts and their underlying mechanisms can be informative in improving the estimation of future drought risk and can help in deciding the management strategies for mitigating drought impacts (Wilhite et al. 2000).

\footnotetext{
Supplemental information related to this paper is available at the Journals Online website: https://doi.org/10.1175/JHM-D-180167.s1.
}

Corresponding author: Ximing Cai, xmcai@illinois.edu
The driving mechanisms of droughts vary at different time scales. At shorter time scales, the land-atmospheric feedback from local evapotranspiration and moisture advection from surrounding regions guided by the regional circulation patterns act as important sources of precipitation and play an important role in the development of seasonal droughts (Betts 2004; Ferguson et al. 2012). On the other hand, oceans play an important role in the drought occurrences at the decadal scale. Previous studies have shown that the meteorological drought frequency in the continental United States (CONUS) oscillates at the multidecadal time scale (Gray et al. 2003), as a result of oscillations in sea surface temperatures (SSTs) in the Pacific Ocean (McCabe and Dettinger 1999; Hoerling and Kumar 2003) and the North Atlantic Ocean (Enfield et al. 2001). This is because the interdecadal variability of precipitation in the 
United States is modulated by the Pacific decadal oscillation (PDO) and the Atlantic multidecadal oscillation (AMO; Dettinger et al. 2001; McCabe et al. 2004). In addition to the decadal-scale internal variability, global warming might also be a pressing factor for future drought risk (Dai 2013; Hoerling et al. 2012; Polade et al. 2017). In this study, we analyze the decadal variability in the severity of seasonal droughts and how it is influenced by the multidecadal oscillations of SSTs and global warming.

Different approaches have been used to understand the relationship between droughts and their drivers. Among the modeling-based studies, general circulation model (GCM) simulations forced with the observed or idealized SST patterns or other external forcings are used to understand the physical mechanisms that lead to the development of droughts (Hoerling and Kumar 2003; Schubert et al. 2004; Mo et al. 2009; Schubert et al. 2009; Ha. Wang et al. 2010; Seager and Hoerling 2014; $\mathrm{Hu}$ and Huang 2009; Burgman and Jang 2015). Meanwhile, statistically based studies have used observation datasets to unravel the relationships between droughts and their driving factors (McCabe and Dettinger 1999; McCabe et al. 2004; Nigam et al. 1999, 2011; Mantua et al. 1997; Mantua and Hare 2002; Cook et al. 2011; Kam et al. 2014a).

While these studies have helped in improving the understanding of droughts and their causing factors, knowledge gaps still exist for the assessment of decadalscale future drought risk, even in the near future. The Fifth Assessment Report of Intergovernmental Panel on Climate Change (IPCC AR5) found low confidence in the future projections of droughts by the GCM models (IPCC 2014). Ault et al. (2013) showed that the GCMs from the fifth phase of the Coupled Model Intercomparison Project (CMIP5) are unable to model the decadal- to multidecadal-scale variability of the hydroclimate of the western United States by using climate proxies. While it has been argued that climate proxies tend to overestimate the low-frequency climate variability (Franke et al. 2013), even studies which have used observational datasets have found that GCMs are unable to model various aspects of meteorological droughts such as low-frequency variability (Ault et al. 2012; Abatzoglou and Rupp 2017; Cheung et al. 2017) and persistence of droughts (Moon et al. 2018).

In this study, we adopt an advanced statistical approach for estimating meteorological drought risk in the near future. We use support vector machines (SVMs; Vapnik 1995) instead of previously used linear regression models to capture the nonlinear relationship between meteorological droughts and their driving factors. We model the decadal changes in severity of seasonal

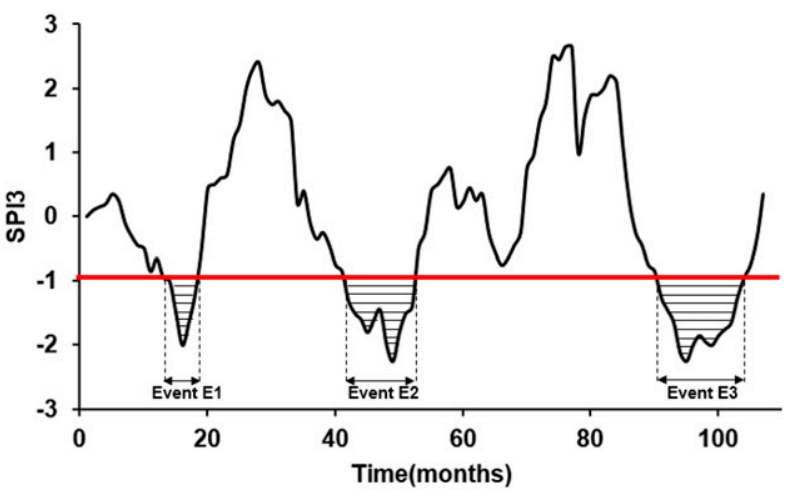

FIG. 1. Definition of drought events. Droughts are defined as periods with SPI3 $\leq-1$. The severity of a drought event is the cumulative deficit of SPI below the threshold, which is the area of the shaded regions in the figure.

meteorological droughts in different regions of the CONUS using SVMs. The SVM models are used to quantify the contributions of internal variability and global warming toward decadal changes in severity of drought events in each region during the past 115 years (1901-2015). The insights gained from the statistical models, regarding the regional-scale drivers and their relationships with droughts, are used for the assessment of regional drought severity in the near future.

\section{Materials and methods}

\section{a. Data and definition of droughts}

This study uses the Climate Research Unit monthly rainfall dataset (CRU TS3.24) that has a $0.5^{\circ}$ spatial resolution and covers the period 1901-2015. A time series of the number of contributing stations to this dataset for each of our study's regions of interest is presented in Fig. S1 in the online supplemental material. The focus of this study is on meteorological droughts, which are defined as deficits in precipitation. The standardized precipitation index (McKee et al. 1993) time series calculated at a 3-month time scale (SPI3) is used to identify drought events in this study. Meteorological drought events are defined as periods with SPI $3 \leq-1$ (moderate droughts). The definition of drought events is illustrated in Fig. 1. In the figure, there are three drought events, E1, E2, and E3. The severity of a drought event is defined as the cumulative deficit of SPI3 below the threshold during the event, which is illustrated by the area of the shaded region for each drought event in Fig. 1.

The calculation of SPI requires fitting a distribution to the precipitation time series accumulated to the time scale of SPI and then transforming the fitted distribution 
to a standard normal distribution. Gamma distribution has been most widely used to model the probability distribution function of monthly precipitation. However, recent studies have shown that it may not always be the best choice for modeling precipitation, especially at the aggregated time scales (Stagge et al. 2015; Svensson et al. 2017). Therefore, we have used the nonparametric method outlined in Farahmand and AghaKouchak (2015) for calculating SPI, in which the empirical distribution function is used instead of fitting a distribution.

We apply a 30-yr moving window to the SPI3 time series to study the temporal changes in the severity of seasonal droughts at the multidecadal scale for each grid point. Since we have a total of 115 years of data, the total number of 30-yr moving windows is 86 and the moving windows have years 1901-30, 1902-31, .. , 1986-2015. Each moving window is denoted by the middle year of its window $t_{w}$. For example, the moving window 1901-30 is denoted by $t_{w}=1915$. In each 30-yr window, drought events are identified using SPI3, as shown in Fig. 1. For each of the drought events, the drought severity is calculated and the empirical distribution function of drought severity is estimated for the drought events that have occurred in the moving window. We then use the empirical distribution function for calculating the 95th percentile of drought severity (S95) for each moving window. Thus, for a moving window with the middle year $t_{w}$, the 95th percentile of drought severity $S 95_{t_{w}}$ is defined as the severity of the drought event with a nonexceedance probability of 0.95 during the moving window:

$$
\operatorname{Pr}\left(S_{t_{w}} \leq \mathrm{S} 95_{t_{w}}\right)=0.95
$$

where $S_{t_{w}}$ denotes the severity of drought events that have occurred during the moving window $t_{w}$. Equation (1) is used for calculating the $\mathrm{S} 95_{t_{w}}$ drought severity for each moving window $t_{w} \in\{1915,1916, \ldots, 2000\}$, which provides a time series of $\mathrm{S} 95_{t_{w}}$. We use statistical models for quantifying the influence of internal variability and global warming on the changes in $S 95_{t_{w}}$ at each grid point. The statistical analysis at the gridpoint scale is then aggregated to the nine climate regions in the CONUS (based on the study of Karl and Koss 1984), as shown in Fig. 2. The nine regions are the Northwest, the Northern Plains, the Upper Midwest, the Ohio Valley, the Northeast, the Southeast, the Southern Plains, the Central Plains, and the Southwest. The number of grid points in each climate region in the rainfall dataset is provided in Table $\mathrm{S} 1$ in the supplemental material.

\section{b. Selection of predictors}

Our predictors for drought are AMO, PDO, and Northern Hemisphere average temperature $(\mathrm{NH}$

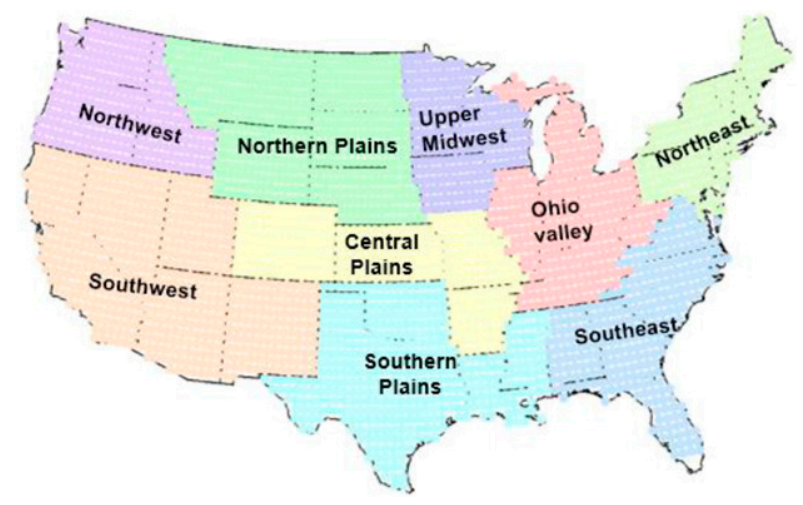

FIG. 2. Climate regions of the CONUS considered in this study.

temperature), which is the temperature averaged over all land and oceans in the Northern Hemisphere. A previous study by McCabe et al. (2004) showed that $\mathrm{AMO}, \mathrm{PDO}$, and $\mathrm{NH}$ temperature are the dominant drivers of multidecadal changes of drought frequency in the CONUS. To confirm that these three variables also have a significant influence on the decadal changes in drought severity, we first perform principal component analysis of S95 time series for the CONUS. Across the CONUS, principal component analysis showed that the first three principal components (PCs) explained $80 \%$ of the observed variability in the S95 drought severity time series at all grid points. The time series of the three PCs are shown in Fig. 3. PC1 explains 31\% of the total variability, PC2 explains $29 \%$ variability, and PC3 explains $20 \%$ variability. The three principal components PC1, PC2, and PC3 show significant correlation $(p<0.001)$ with the 30 -yr moving averages of AMO, $\mathrm{PDO}$, and $\mathrm{NH}$ temperature, respectively. The correlation between PC1 and AMO is 0.78 (Fig. 3a), between PC2 and PDO is -0.75 (Fig. 3b), and between PC 3 and $\mathrm{NH}$ temperature is 0.73 (Fig. 3c).

The spatial distributions of the loadings of the three principal components are shown in Fig. 4 along with the correlation coefficients between the S95 drought severity time series and the 30-yr moving averages of AMO, PDO, and $\mathrm{NH}$ temperature. Loading refers to the correlation coefficient between the principal components and the time series at a given grid point. As can be seen from Fig. 4, the loadings of PC1 show a similar spatial distribution as the correlation coefficient between the S95 drought severity and the 30-yr moving average of AMO. The spatial correlation between the two patterns is 0.72 . Similarly, the loadings of PC2 show a very similar pattern as that of the correlation coefficient between S95 drought severity and the PDO moving average (spatial correlation 0.95), and the loadings of PC3 show a similar pattern 

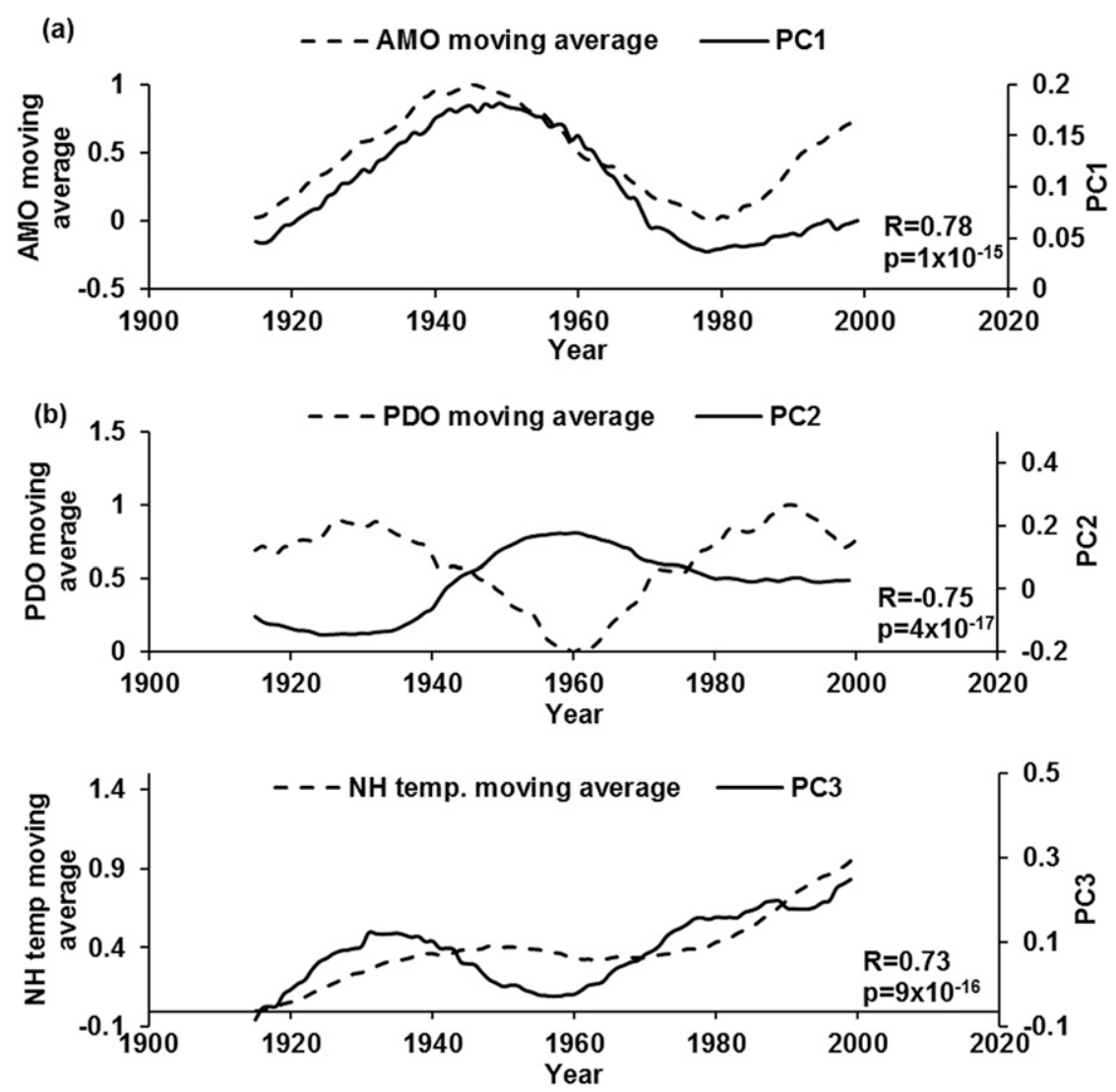

FIG. 3. Time series of the three principal components of S95 drought severity time series plotted with the 30-yr moving average time series of AMO, PDO, and NH temperature. The moving averages of AMO, PDO, and $\mathrm{NH}$ temperature have been scaled between 0 and 1 . The correlation coefficients $R$ between the PCs and moving averages of AMO, PDO, and NH temperature are also shown along with their corresponding $p$ values.

as the correlation coefficients of S95 drought severity with the moving average of $\mathrm{NH}$ temperature (spatial correlation 0.80 ). The average loading of the three principal components in each climate region is shown in Table 1.

We also tried moving windows of lengths 10,20 , and 40 years. The correlation of the principal components with the moving averages of AMO, PDO and $\mathrm{NH}$ temperature were the highest when a 30-yr moving window was used (Table 2) and hence the 30-yr window was selected. Thus, based on the results in Figs. 3 and 4, AMO, PDO, and NH temperature can be used as the predictors of multidecadal variability of drought severity in the CONUS. El Niño-Southern Oscillation (ENSO), which has a significant influence on the interannual variability of climate in the CONUS, was not found to have a significant correlation with any of the three principal components at the 30-yr time scale, and hence was not selected for further analysis (not shown). This might be because we are using a 30-yr time scale, whereas ENSO's cycle is about 2-7 years and its decadal variability is similar to PDO.

\section{c. Support vector machines}

While AMO and PDO represent the influence of the internal variability of the climate, the trend in the $\mathrm{NH}$ temperature time series contains the global warming signal. The strong correlation between $\mathrm{PC} 3$ and the $\mathrm{NH}$ temperature time series shows that the multidecadal changes in drought severity in the CONUS have been influenced by global warming. That is why we do not detrend the $\mathrm{NH}$ temperature time series, but rather use the original NH temperature time series so that the influence of global warming on drought severity can be identified via the statistical analysis presented in this study. While we have used NH temperature as a proxy for global warming, it is important to note that $\mathrm{NH}$ temperature is also influenced by the internal variability of the climate. This means that AMO and PDO, which have been selected to represent the internal variability, 
(a)

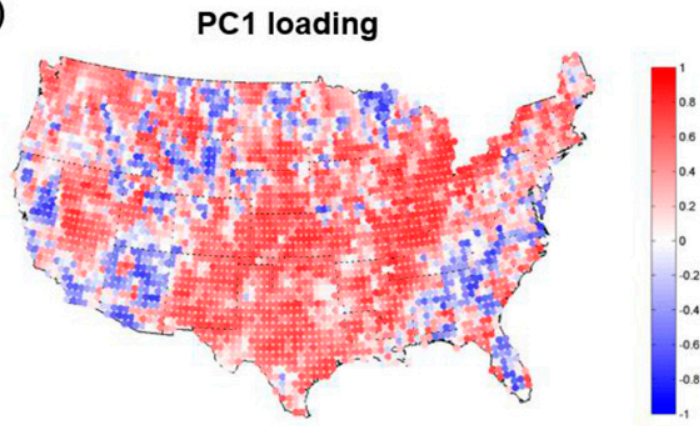

(b)

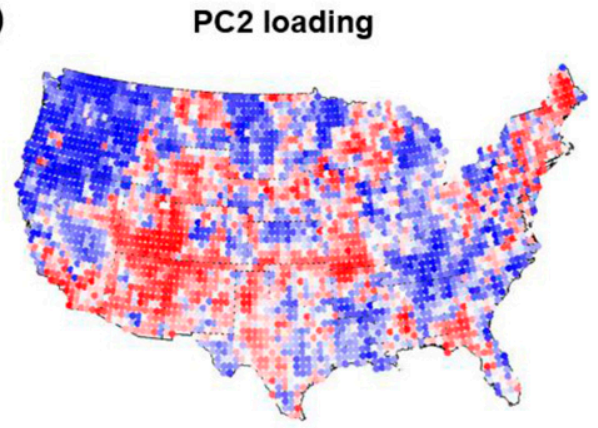

(c)

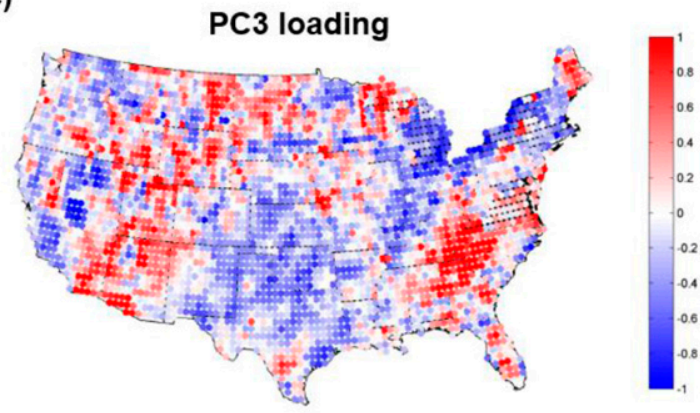

(d)

\section{AMO-drought severity correlation}

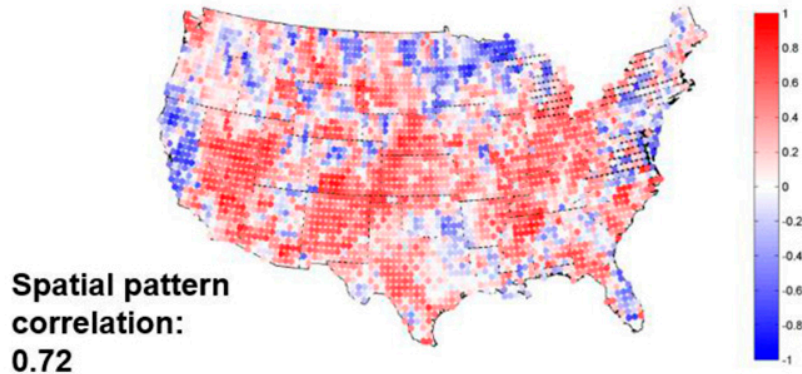

(e)

PDO-drought severity correlation

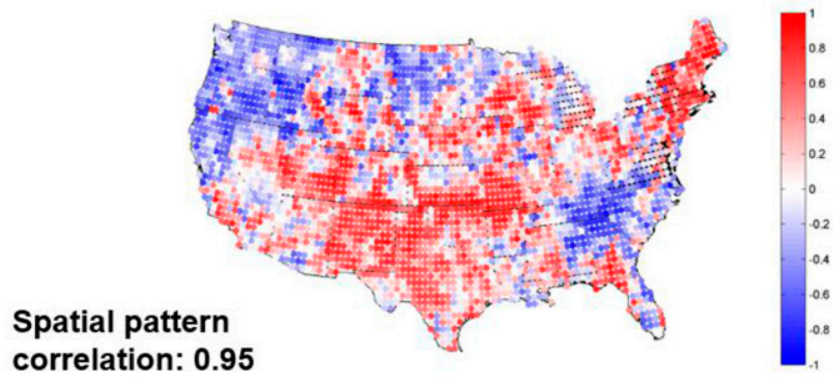

(f)

$\mathrm{NH}$ temp.-drought severity correlation

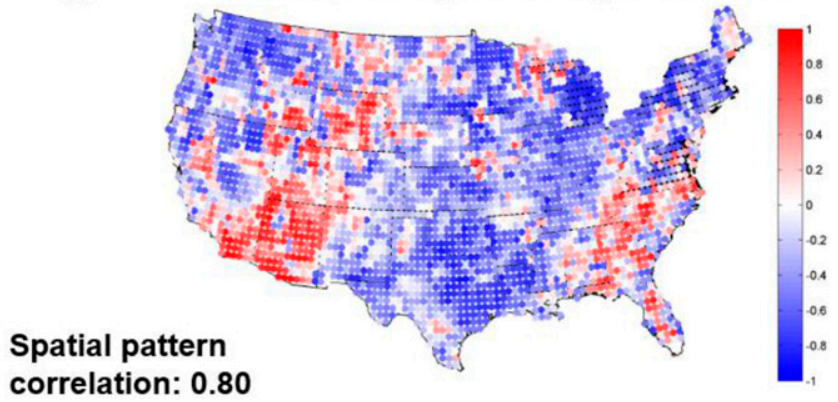

FIG. 4. Spatial distribution of the loadings of the three principal components (a) PC1, (b) PC2, and (c) PC3. Correlation coefficient between S95 drought severity time series and moving average of (d) AMO, (e) PDO, and (f) NH temperature. The spatial correlation between the loadings and correlation coefficients are also shown for the three PCs.

can also influence NH temperature, implying that the three predictors used in this analysis are not necessarily independent. That is why we use SVMs in this study to capture the nonlinearity in relationships while handling the correlation between predictor variables by projecting them into a higher dimensional space. We utilize the ability of SVMs to model nonlinear relationships for quantifying the impacts of internal variability and global warming on the decadal changes in drought severity in different parts of the CONUS.

Here we briefly introduce the structure of SVMs. If $\mathbf{x}_{i} \in \mathbf{R}^{\mathrm{n}}$ denotes the $n$-dimensional input variables and $y_{i}$ denotes the output variables in the training dataset, SVM projects the input variables into a higher dimensional space through a nonlinear transformation $\phi(\mathbf{x})$ such that the nonlinear relation between the input and output variables in the original space can be transformed into a linear function $f$ given by

$$
\hat{y}=f(\mathbf{x})=\mathbf{w}^{\mathrm{T}} \phi(\mathbf{x})+b,
$$

where $\hat{y}$ is the model predicted output, $\mathbf{w} \in \mathbf{R}^{n_{h}}$ and $b \in \mathbf{R}$ are the SVM model parameters, and $n_{h}$ is the dimension of the transformed space. Parameters $\mathbf{w}$ and $b$ are obtained by minimizing the following cost function

$$
\psi_{\epsilon}\left(\mathbf{w}, \varepsilon, \varepsilon^{*}\right)=\frac{1}{2} \mathbf{w}^{\mathrm{T}} \mathbf{w}+C \sum_{i=1}^{N}\left(\varepsilon_{i}+\varepsilon_{i}^{*}\right)
$$

subjected to constraints 
TABLE 1. Average loadings of the three principal components in each climate region.

\begin{tabular}{lrrr}
\hline \hline Climate region & \multicolumn{1}{c}{ PC1 } & PC2 & PC3 \\
\hline Northwest & 0.07 & -0.37 & -0.30 \\
Upper Midwest & -0.07 & 0.18 & -0.37 \\
Northern Plains & 0.16 & -0.02 & -0.10 \\
Ohio Valley & 0.32 & 0.04 & -0.36 \\
Central Plains & 0.31 & 0.36 & -0.28 \\
Northeast & -0.01 & 0.36 & -0.34 \\
Southwest & 0.28 & 0.18 & 0.06 \\
Southeast & 0.15 & -0.16 & 0.10 \\
Southern Plains & 0.19 & 0.34 & -0.44 \\
\hline
\end{tabular}

$$
\begin{aligned}
y_{i}-\hat{y}_{i} \leq \epsilon+\varepsilon_{i}, & i=1,2, \ldots, N, \\
-y_{i}+\hat{y}_{i} \leq \epsilon+\varepsilon_{i}^{*}, & i=1,2, \ldots, N, \\
\varepsilon_{i} \geq 0, & i=1,2, \ldots, N, \quad \text { and } \\
\varepsilon_{i}^{*} \geq 0, & i=1,2, \ldots, N,
\end{aligned}
$$

where $\varepsilon_{i}$ and $\varepsilon_{l}^{*}$ are positive slack variables, $\epsilon$ controls the sensitivity of the loss function, $N$ is the number of data points in the training dataset, and $C$ is a positive real constant. By solving the problem defined in Eqs. (3)-(7) by the method of Lagrange multipliers, one can obtain

$$
\mathbf{w}=\sum_{i=1}^{N}\left(\alpha_{i}-\alpha_{i}^{*}\right) \phi\left(\mathbf{x}_{i}\right),
$$

where $\alpha_{i}$ and $\alpha_{i}^{*}$ are the Lagrange multipliers corresponding to constraints in Eqs. (4) and (5). Thus, the linear function $f$ in Eq. (2) can be rewritten as

$$
\hat{y}=f(\mathbf{x})=\sum_{i=1}^{N}\left(\alpha_{i}-\alpha_{i}^{*}\right) K\left(\mathbf{x}_{i}, \mathbf{x}\right)+b
$$

where $K\left(\mathbf{x}_{i}, \mathbf{x}\right)$ is the kernel function, which is given by

$$
K\left(\mathbf{x}_{i}, \mathbf{x}_{j}\right)=\phi\left(\mathbf{x}_{i}\right)^{\mathrm{T}} \phi\left(\mathbf{x}_{j}\right) .
$$

In this study, we use the Gaussian radial basis function (RBF) kernel, which is given by

$$
K\left(\mathbf{x}_{i}, \mathbf{x}_{j}\right)=\exp \left(-\frac{\left\|\mathbf{x}_{i}-\mathbf{x}_{j}\right\|^{2}}{2 \sigma^{2}}\right) .
$$

We select the RBF kernel because of two advantages: 1) the nonlinear mapping function allows effective modeling of highly nonlinear relationships between input and output variables, and 2) RBF kernel has only one parameter. The training of SVMs with RBF kernels thus involves the selection of two parameters, namely, RBF kernel width $\sigma$ and the cost function parameter $C$. In this study, SVM was implemented using the e1071 package in R (Meyer et al. 2017). In this package, parameters $C$ and $\sigma$ are determined using a grid-search algorithm (Hsu et al. 2004). The algorithm tests an exponential sequence of $C$ and $\sigma$ values (e.g., $\left.2^{-10}, 2^{-9}, \ldots, 2^{10}\right)$ and determines the best combination based on the model performance in the validation dataset.

\section{d. Sensitivity analysis}

We model the S95 drought severity at each grid point as a function of the 30-yr moving average of AMO, PDO, and NH temperature using SVMs. The SVM models provide a nonlinear relationship between the three predictors and the S95 drought severity time series. However, SVMs do not provide an analytical expression of this relationship. Therefore, to quantify the influence of AMO, PDO, and $\mathrm{NH}$ temperature on the decadal changes in drought severity, we perform sensitivity analysis of SVM models. This was done as follows: first, the values of the 30-yr moving averages of AMO, $\mathrm{PDO}$, and $\mathrm{NH}$ temperature were set equal to their respective long-term means during 1901-2015 to predict the S95 drought severity (S0) using the SVM models. Next, one of the three predictors $p$ was altered by unit standard deviation of its historical distribution, while keeping the other two constant and again the $\mathrm{S} 95$ drought

\begin{tabular}{|c|c|c|c|c|c|c|}
\hline \multirow[b]{2}{*}{ Moving window length (yr) } & \multicolumn{3}{|c|}{ Temporal correlation } & \multicolumn{3}{|c|}{ Spatial correlation } \\
\hline & AMO-PC1 & PDO-PC2 & NH temp-PC3 & AMO-PC1 & PDO-PC2 & NH temp-PC3 \\
\hline 10 & 0.21 & -0.28 & 0.45 & 0.35 & 0.55 & 0.29 \\
\hline 20 & 0.51 & -0.59 & 0.62 & 0.43 & 0.75 & 0.56 \\
\hline 30 & 0.78 & -0.75 & 0.73 & 0.72 & 0.95 & 0.80 \\
\hline 40 & 0.77 & -0.75 & 0.76 & 0.77 & 0.94 & 0.77 \\
\hline
\end{tabular}
severity was calculated $\left(\mathrm{S}_{p}\right)$. The sensitivity $(\mathrm{St})$ of drought severity $\mathrm{S} 95$ to the predictor $p$ is calculated as

$$
\mathrm{St}_{p}=\frac{\mathrm{S}_{p}-\mathrm{S} 0}{\mathrm{~S} 0} \times 100
$$

where $p=\mathrm{AMO}, \mathrm{PDO}$, and $\mathrm{NH}$ temperature.

TABLE 2. Temporal correlation between PC-predictor time series and spatial correlation between PC loadings and S95-predictor correlation coefficients. Bold text highlights the $30-\mathrm{yr}$ window, which has the strongest temporal and spatial correlations. 
We perform the sensitivity analysis of the SVM models developed for each grid point in the rainfall dataset and then analyze the results of sensitivity analysis at the regional scale for the nine climate regions. To determine if the sensitivity values of a predictor for a given climate region are statistically significant, we employ the Wilcoxon-Mann-Whitney (WMW; Wilcoxon 1945) rank test. It is a nonparametric test to test whether one group of data tends to produce larger observations than the second group. If we want to determine the statistical significance of predictor $p$ in a climate region $k$, we first calculate the values $\mathrm{S} 0$ and $\mathrm{S}_{p}$ at each point in the climate region as described above. We then set the null hypothesis that the sensitivity to predictor $p$ is not statistically significant, that is,

$$
H_{0}: \operatorname{Pr}\left(\mathrm{S} 0_{p}^{k}>\mathrm{S} 0^{k}\right)=0.5,
$$

where $\mathrm{S}^{k}$ and $\mathrm{S}_{p}^{k}$ represent the $\mathrm{SVM}$ predicted $\mathrm{S} 95$ values for the historical mean and unit standard deviation from the mean for predictor $p$, respectively, at grid points in climate region $k$. The null hypothesis states that the probability of $\mathrm{S}_{p}^{k}$ value being higher than $\mathrm{S} 0^{k}$ value for any given point in the climate region $k$ is 0.5 . We perform the two-sided WMW rank test, in which the alternate hypothesis is

$$
H_{1}: \operatorname{Pr}\left(\mathrm{S}_{p}^{k}>\mathrm{S}^{k}\right) \neq 0.5 .
$$

Thus, the rejection of null hypothesis $H_{0}$ means that the sensitivity of a climate region with respect to the predictor $p$ is statistically significant. We perform the test at $5 \%$ significance level.

We also perform the WMW rank test to determine the dominant driver of decadal variability of drought severity for each climate region. To determine the dominant driver, we compare the sensitivity values for the three predictors. Since the sensitivity values can be both positive and negative, we compare the absolute sensitivity values in the hypothesis test. The null hypothesis is set as

$$
H_{0}: \operatorname{Pr}\left(\left|\mathrm{St}_{\mathrm{p} 1}^{k}\right|>\left|\mathrm{St}_{\mathrm{p} 2}^{k}\right|\right)=0.5,
$$

where $\mathrm{St}_{\mathrm{p} 1}^{k}$ and $\mathrm{St}_{\mathrm{p} 2}^{k}$ represent the sensitivity values of grid points in climate region $k$ with respect to predictors $\mathrm{p} 1$ and $\mathrm{p} 2$, respectively. In this case, we perform the onesided test, in which the alternate hypothesis is set as

$$
H_{1}: \operatorname{Pr}\left(\left|\mathrm{St}_{\mathrm{p} 1}^{k}\right|>\left|\mathrm{St}_{\mathrm{p} 2}^{k}\right|\right)>0.5 \text {. }
$$

The rejection of the null hypothesis in this case means that the sensitivity values of the grid points in climate region $k$ with respect to the predictor $\mathrm{p} 1$ are greater than those with respect to predictor $\mathrm{p} 2$. We use this test for comparing the sensitivity values of all three pairs of predictors. The dominant driver of a climate region is chosen as the predictor whose sensitivity values are found to be larger than the other two predictors at $5 \%$ significance level.

The monthly time series of AMO and PDO were obtained from the National Oceanic and Atmospheric Administration (NOAA; https://www.esrl.noaa.gov/ psd/data/timeseries/AMO; https://www.ncdc.noaa.gov/ teleconnections/pdo), and the NH average temperature data were taken from the CRU dataset (www.cru. uea.ac.uk/cru/data/temperature).

\section{Results}

\section{a. Temporal patterns in drought severity at the decadal scale}

Figure 5 displays the time series of the S95 drought severity across the moving windows in different regions of the CONUS. In the figure, the $x$ axis shows the middle year of a 30-yr moving window. Northern regions of the CONUS, which include the Northwest, Northern Plains, and Upper Midwest, show two local maxima of drought severity; one during the 1920-50 and the other during the 1970-90 moving windows (Figs. 5a-c). The Ohio Valley shows high drought severity up to the 1940 window, followed by a decrease in the subsequent years (Fig. 5d). The Central Plains and the Northeast regions experienced high drought severity during 1945-70 and 1950-80 windows, respectively, which was followed by a decline in the following years (Figs. 5e,f). In the Southeast and the Southwest, an increase in drought severity is evident since the 1970s windows (Figs. 5g,h). The drought severity shows a decline in the Southern Plains region up to the year 1990 but increases thereafter (Fig. 5i).

\section{b. Training of SVM models}

For each grid point in the observation dataset, we have a time series of the S95 drought severity across 85 moving windows. Thus, each time series comprises 85 data points. Out of these, 20 data points were used for training SVM models and the remaining 65 for testing the performance of SVM models. The 20 data points used for training were evenly spaced across the observation period, so that data points from all periods were represented in the training dataset. This is important because the effect of global warming is expected to be more significant in the second half of the dataset. However, the 20 data points selected for training are 

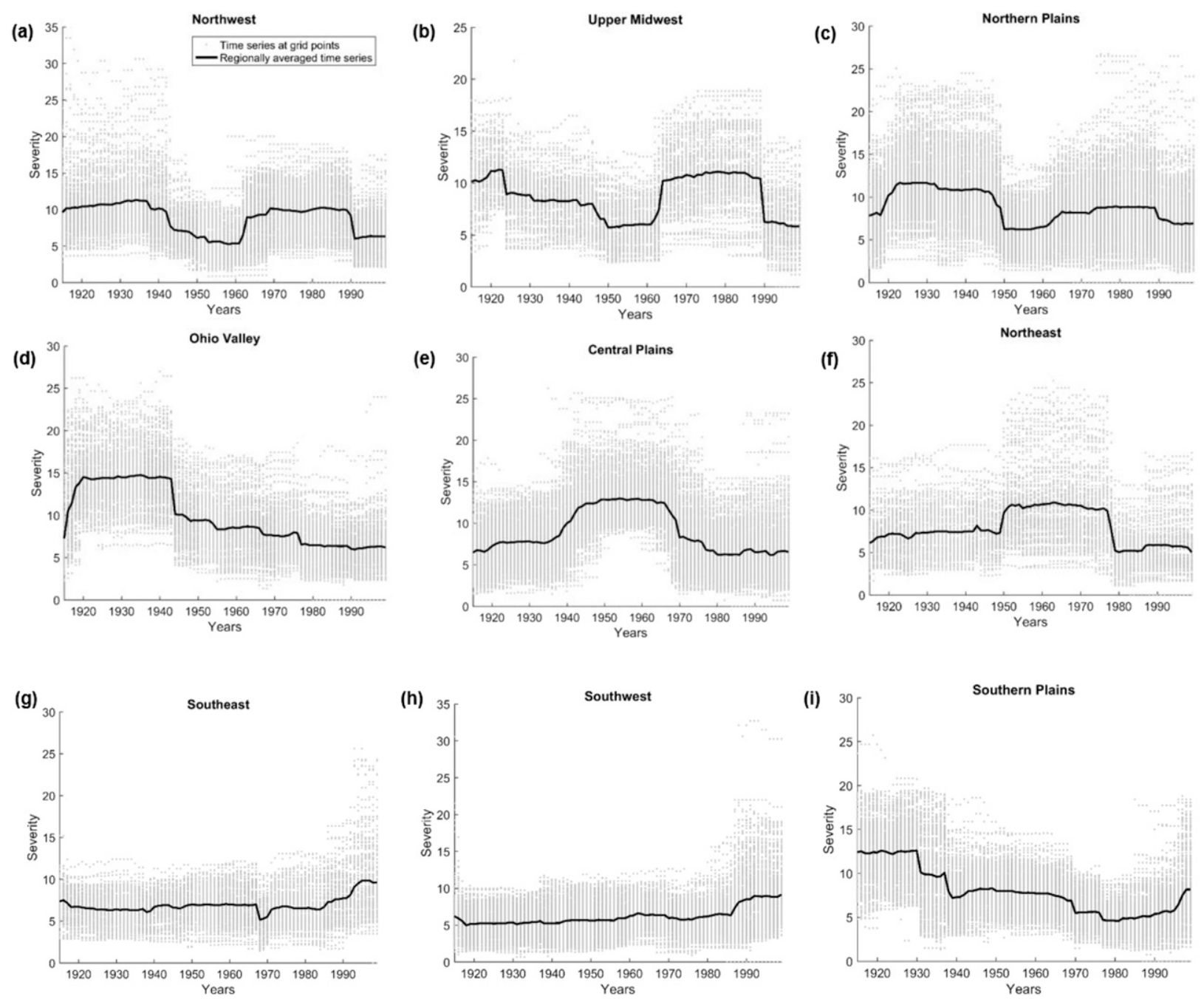

FIG. 5. Time series of S95 drought severity plotted for different regions in the CONUS. Gray dots represent the time series for individual grid points in the climate regions, and the solid black line represents the regionally averaged time series. Years on the $x$ axis represent the middle years of the 30 -yr moving windows.

still not independent of each other as there is some overlap between these moving windows. The correlation of training data samples can lead to overoptimistic estimates of prediction error and potentially erroneous scientific conclusion (Hastie et al. 2009). To overcome this problem, we have used a modified form of leave-one-out cross validation, proposed by Roberts et al. (2017). In this technique, one of the training data samples is selected as the validation dataset, while the remaining nondependent data samples (nonoverlapping windows) are used for training. This exercise is repeated until each of the training samples have been selected as the validation dataset once. The final parameter selection is based on the performance across each of these cases. The comparison of the observed and predicted S95 values for the testing dataset for all grid points are shown in Fig. 6. The performance of the SVM models in the nine climate regions, indicated by the high $R^{2}$ values in Fig. 6, shows that the SVM models are able to capture the decadal changes in drought severity reasonably well in most of the regions of the CONUS and can hence be used to understand the role of individual drivers in the decadal variability of drought severity. For comparison, we also show the performance of multiple linear regression models with the same set of predictors (AMO, PDO, NH temp) in Fig. 7. We used the same training and testing datasets for the multiple linear regression models as those used for the SVM models (using 20 data points for training and 65 for testing). It can be seen that performance of SVMs (Fig. 6) is superior to that of multiple linear regression 

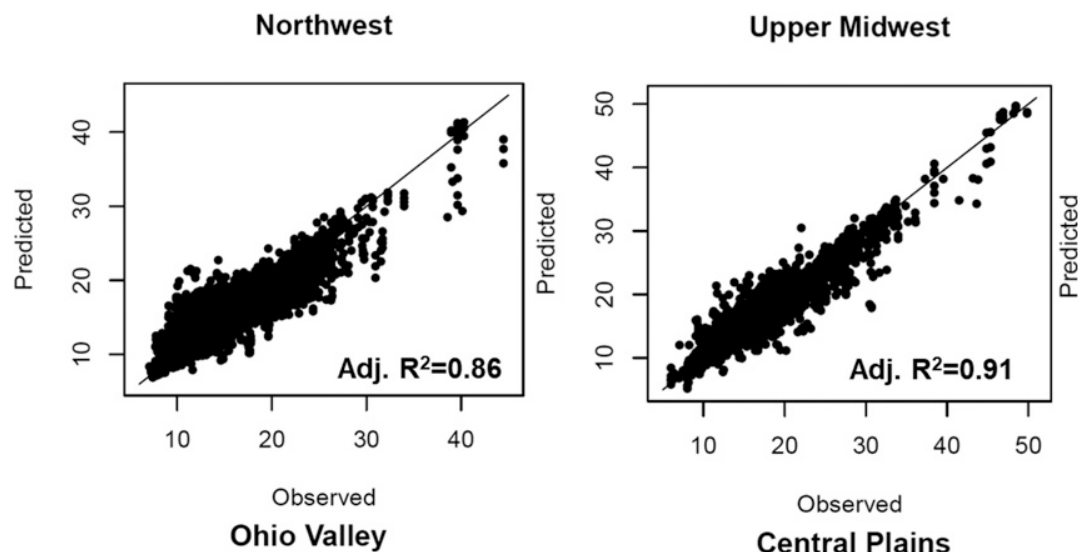

Central Plains

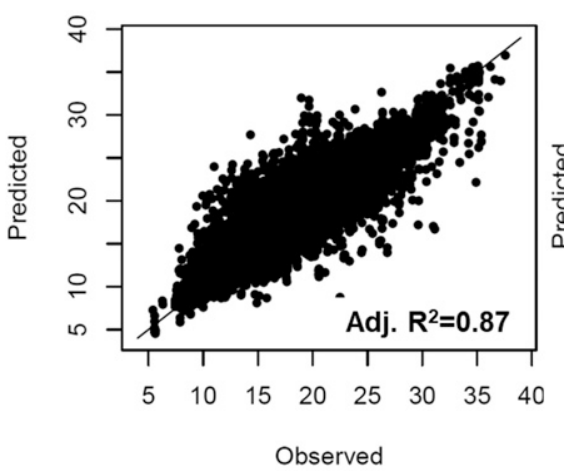

Southwest

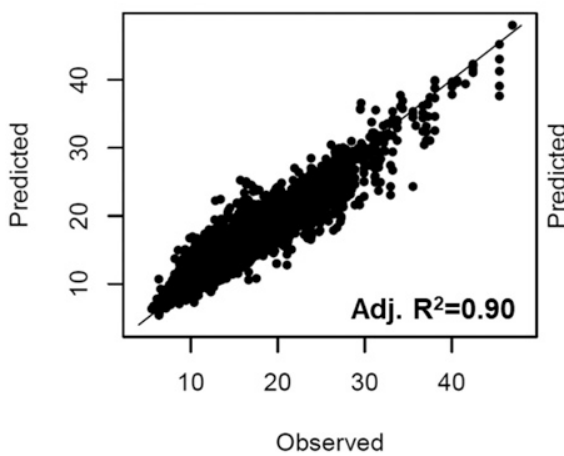

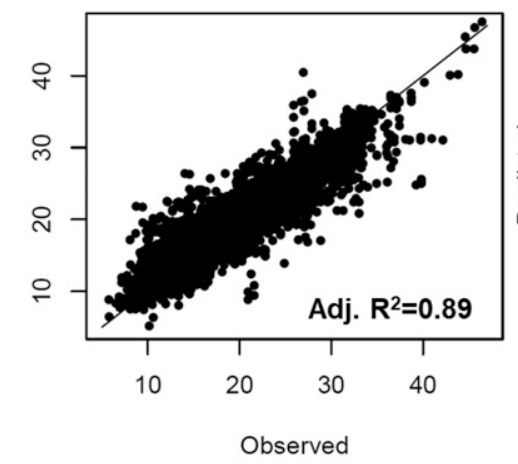

Southeast

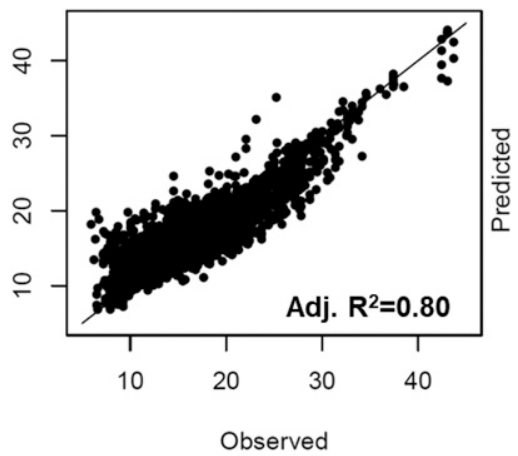

Northern Plains

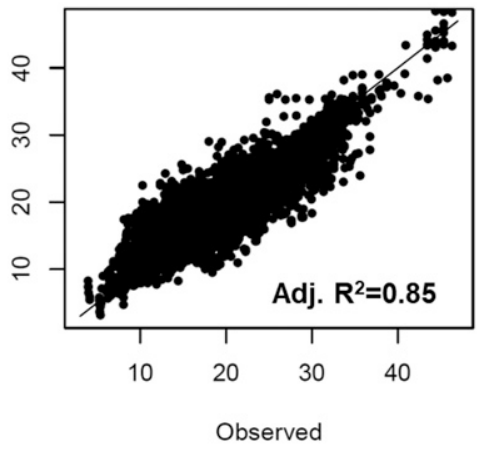

Northeast

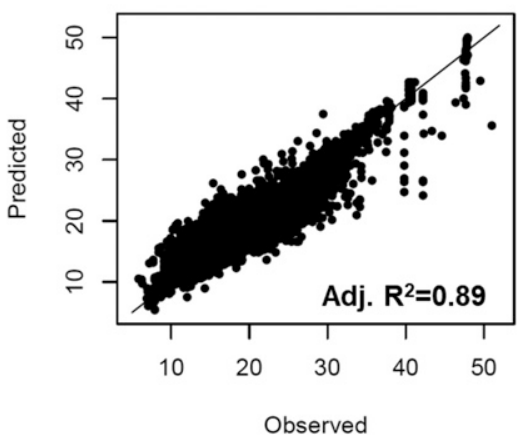

Southern Plains

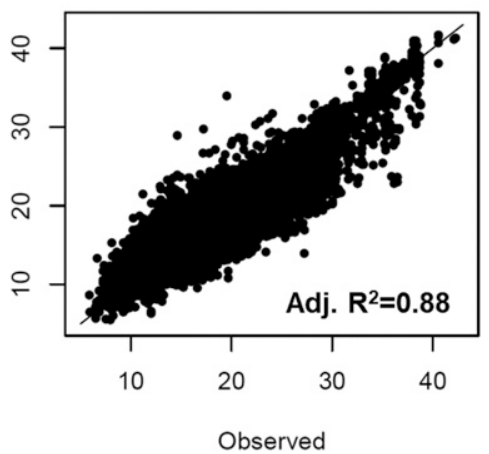

FIG. 6. Comparison of observed and predicted S95 drought severity by SVM models in the testing dataset for different regions.

models in all climate regions with higher squared correlations, especially in Southern Plains and Southeast United States.

\section{c. Regional drivers of droughts}

Next, we perform sensitivity analysis of the SVM models to understand how the spatial and temporal patterns shown in Fig. 5 are influenced by AMO, PDO, and $\mathrm{NH}$ average temperature. The time series of AMO and PDO show that at the multidecadal scale, AMO had a positive phase shift in the 1990s and PDO shifted toward its negative phase around the year of 2000, while
NH temperature has been increasing since 1980 (Fig. 8). Based on the persistence of these oscillations observed in the past (Chylek et al. 2012; Wu et al. 2011), we perform the sensitivity analysis of the SVM models for an increase in AMO (to represent positive phase), a decrease of PDO (to represent negative phase), and an increase in $\mathrm{NH}$ temperature, as this information is the most relevant for the assessment of drought severity in the near future (10-30 years). However, the future evolution of AMO and PDO is not certain, as they may be influenced by global warming. Future projections of AMO in CMIP5 models are highly uncertain as the 

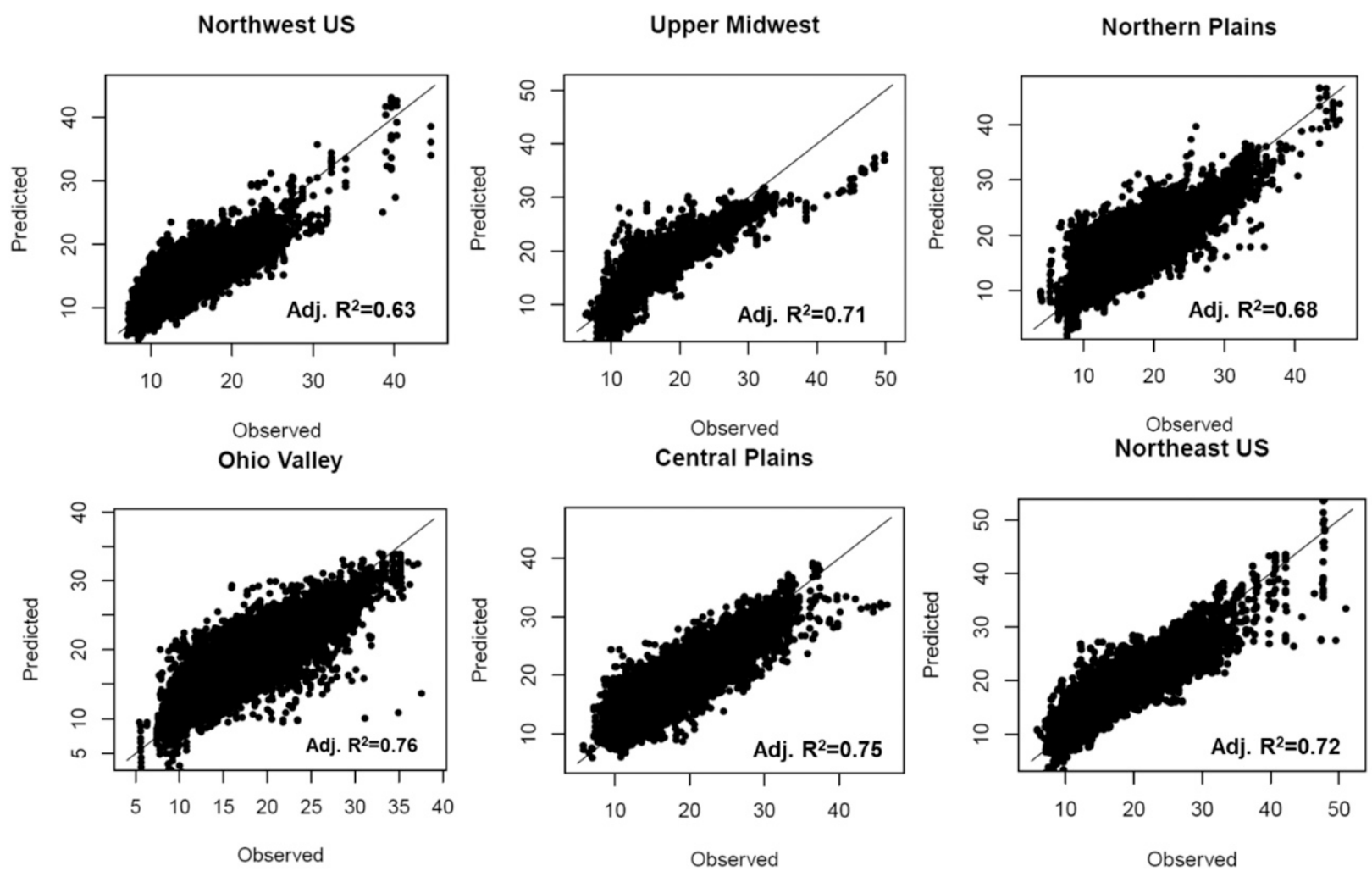

Southeast US
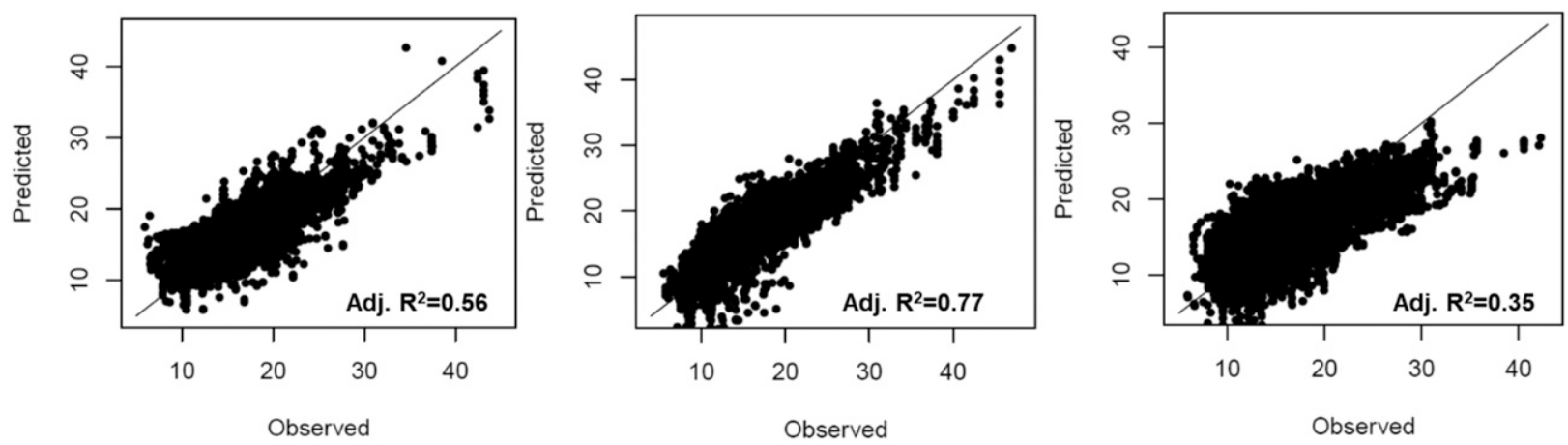

FIG. 7. Comparison of observed and predicted S95 drought severity by multiple linear regression models in the testing dataset for different regions.

GCM models are unable to model the underlying mechanism of AMO (Sheffield et al. 2013). Lapp et al. (2012) generated future projections of PDO using GCMs and concluded that global warming is not expected to have any significant impact on PDO in the early part of the twenty-first century. However, several other studies have shown that the cycles of PDO may become shorter by the end of the twenty-first century under the influence of global warming (Zhang and Delworth 2016; Wang and Li 2017). Therefore, to consider the possibility of phase shift of AMO and PDO in the near future, we also perform sensitivity analysis for a decrease in AMO and an increase in PDO for a more comprehensive assessment of possible drought severity conditions in the near future. The kernel density estimates of the historical probability density functions of the 30-yr moving averages of AMO, PDO, and NH temperature during 1901-2015 are also shown in Fig. 8, along with the mean and the unit standard deviation from the mean of each variable. The positive and negative standard deviations from the historical mean are used to estimate the influence of positive and negative phase shifts of the predictors on drought severity. 


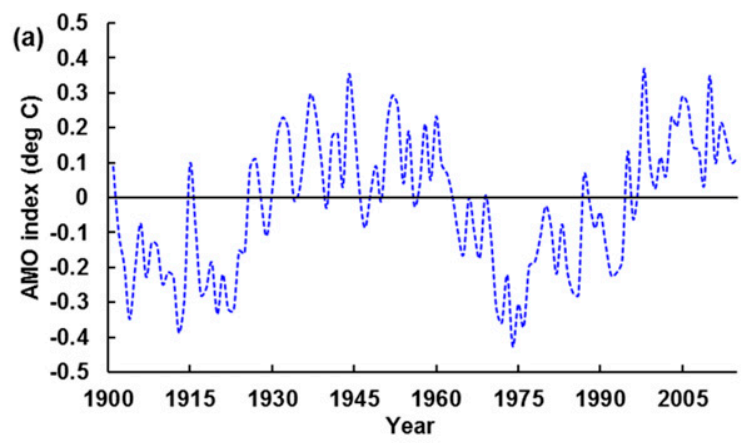

(d)
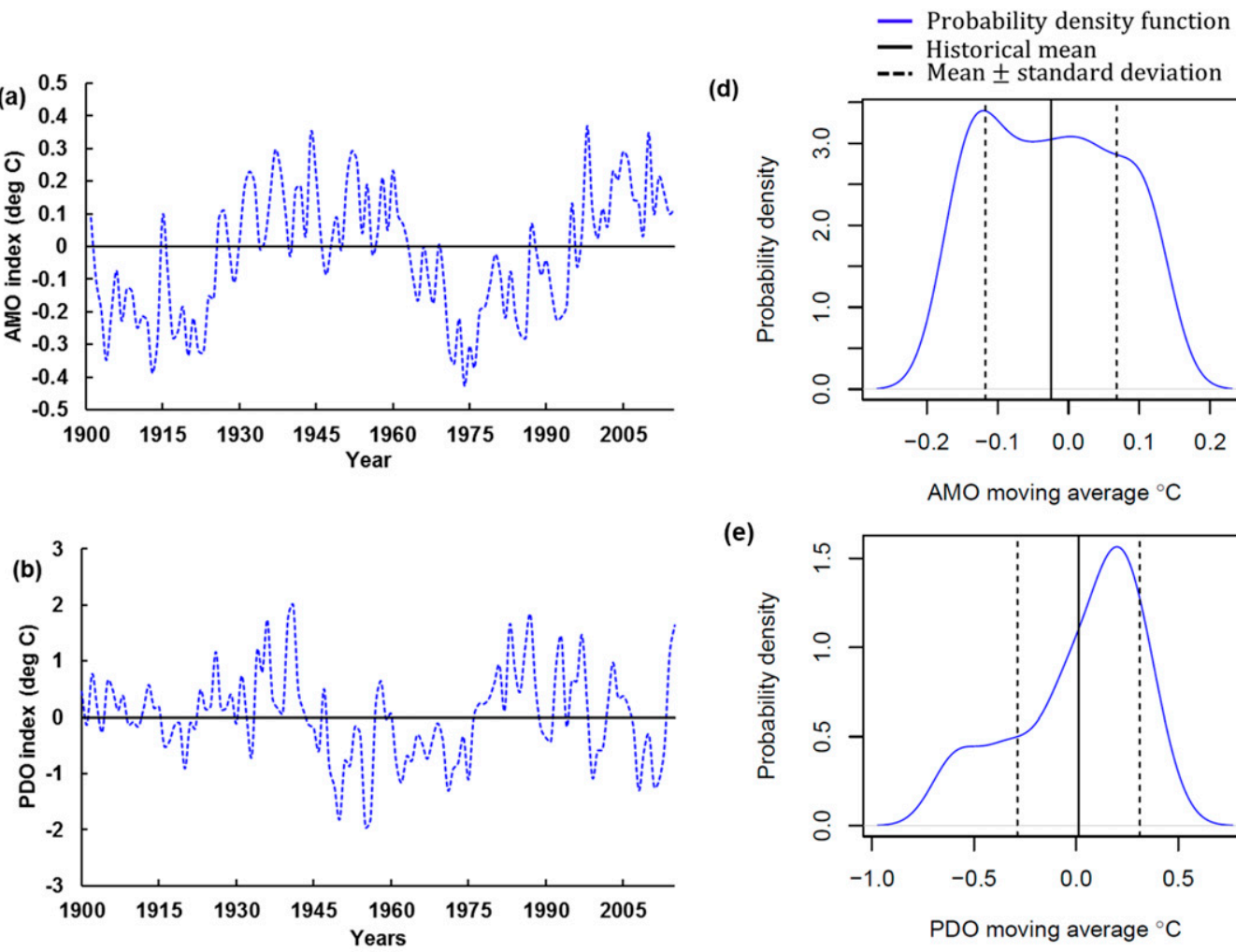

(e)
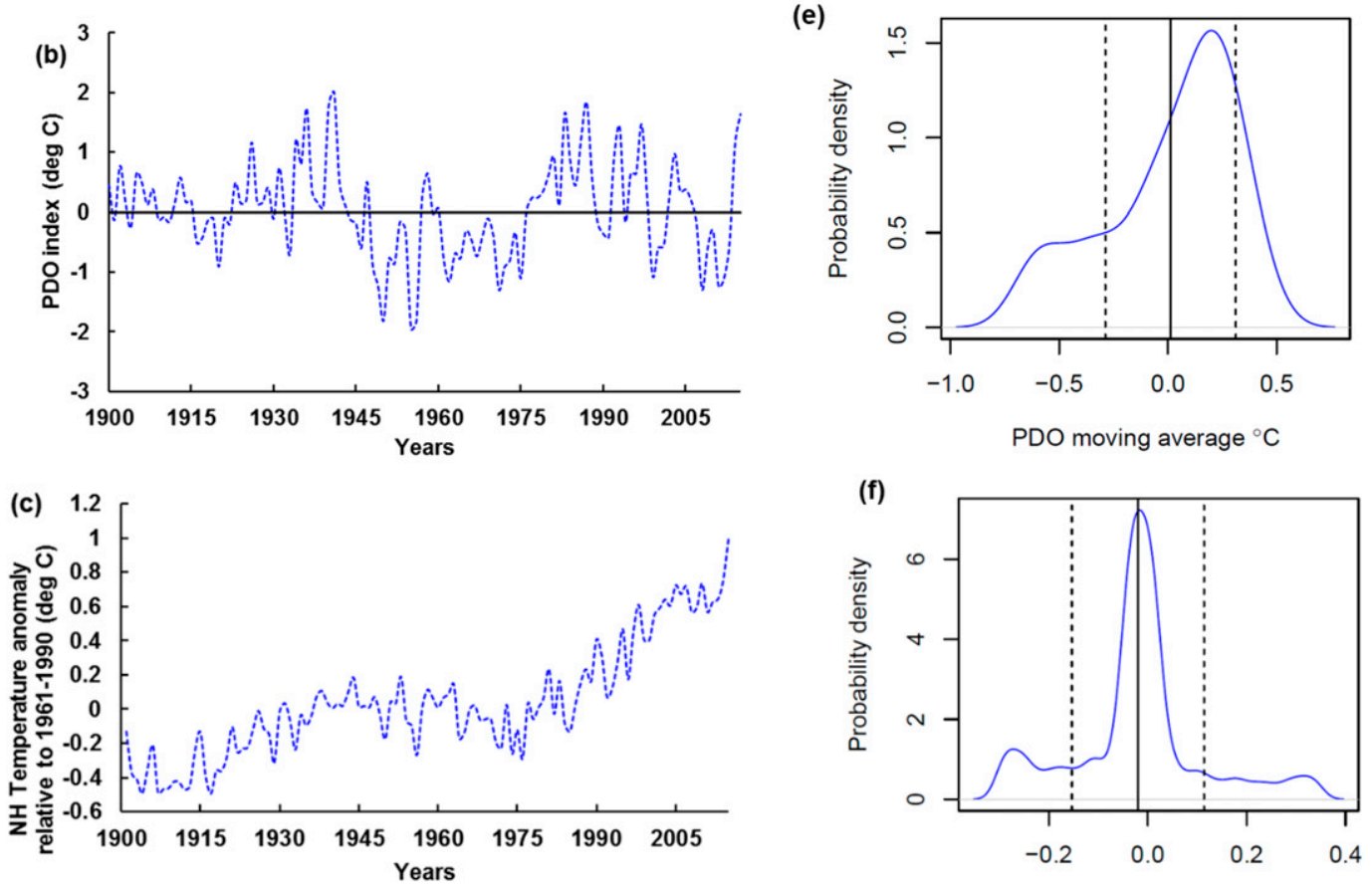

$\mathrm{NH}$ temp moving average ${ }^{\circ} \mathrm{C}$

FIG. 8. Time series of the (a) AMO, (b) PDO, and (c) NH temperature anomaly calculated with respect to 196190. Also shown are the kernel density estimate of the probability density functions of 30-yr moving averages of the (d) AMO, (e) PDO, and (f) NH temperature anomaly with respect to 1961-90. The density functions are calculated for the period 1901-2015. The mean and unit standard deviation from the mean are also shown in the figures. Data sources: NOAA for AMO and PDO, CRU for NH temperature time series.

Figure 9 shows the results of sensitivity analysis of the SVM models, that is, the percentage changes in the magnitude of S95 drought severity in different regions of the CONUS are shown for a positive change in AMO, a negative change in $\mathrm{PDO}$, and a positive change in $\mathrm{NH}$ temperature by unit standard deviation of the historical distribution of each predictor. It should be noted that the sensitivity values represent the effect of positive and negative phase shifts of predictor variables on the changes in drought severity, and not percentage changes in drought severity with respect to any particular year in the record. The sensitivity analysis is performed for individual grid points and hence the distributions of sensitivity values are shown for each region; the heights of the gray bars represent the median sensitivity values and the whiskers represent the interquartile range of sensitivity values in each region. The statistical significance of the sensitivity values for each predictor is evaluated using the two-sided WMW rank test at 5\% significance level. Statistically significant predictors for each region are marked with an asterisk symbol in Fig. 9. The median baseline severity [S0 in Eq. (12)] and the median 
(a) Northwest US

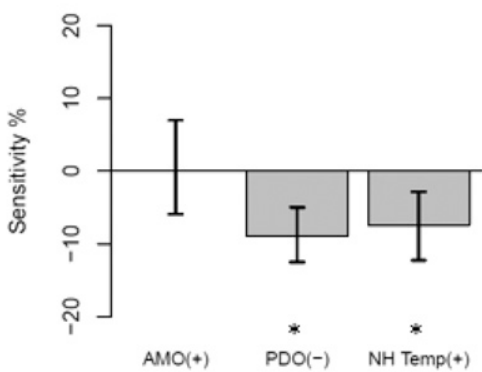

(d) Ohio Valley

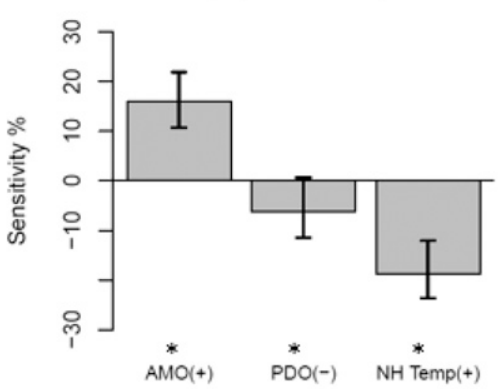

(g) Southwest US

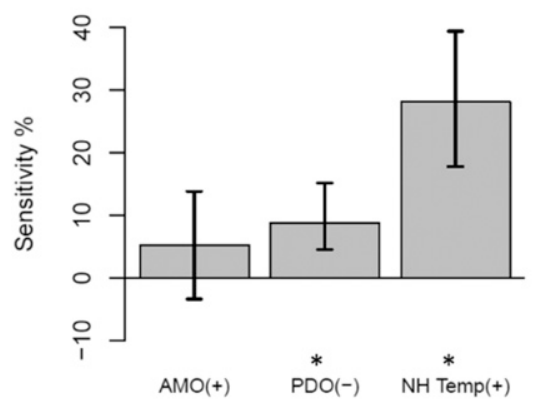

(b) Upper Midwest

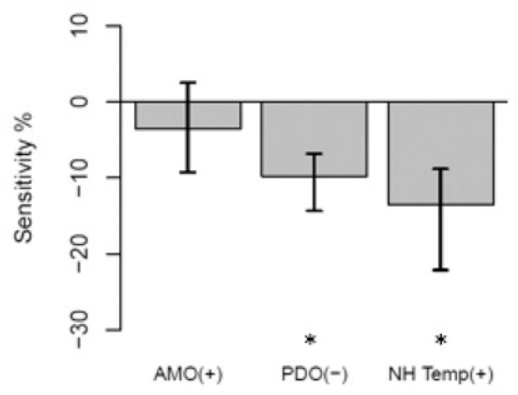

(e) Central Plains

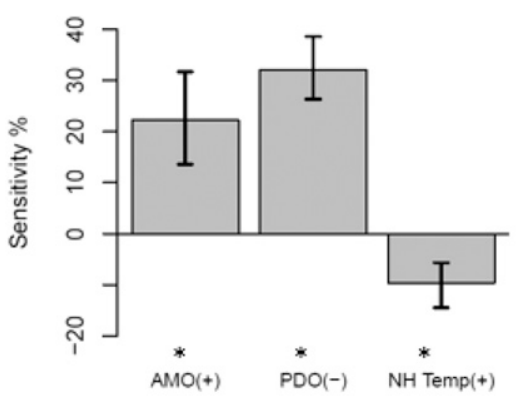

(h) Southeast US

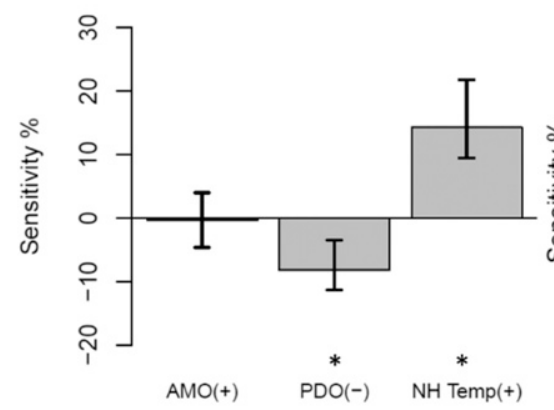

(c) Northern Plains

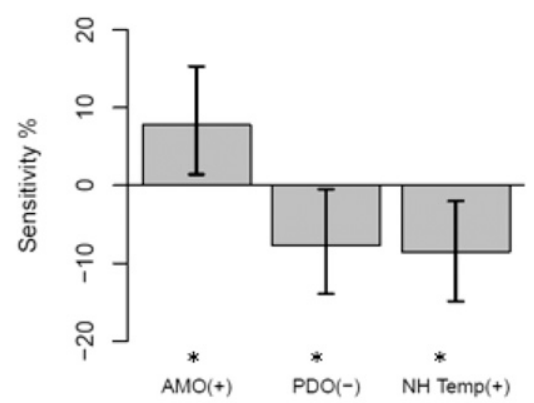

(f) Northeast US

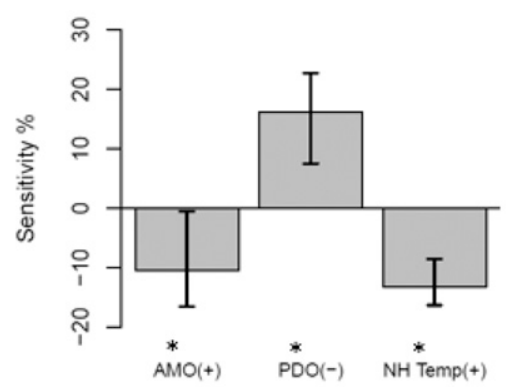

(i) Southern Plains

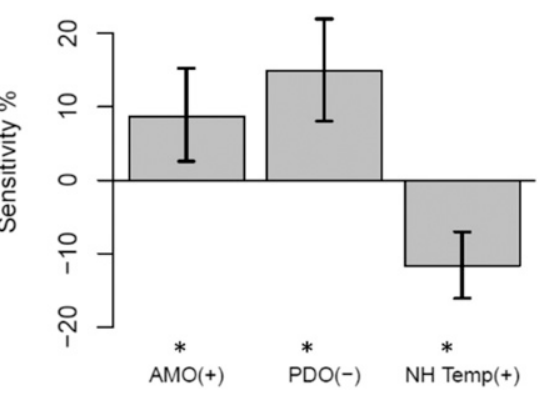

FIG. 9. Percentage change in the magnitude of the S95 drought severity due to an increase in AMO, a decrease in PDO, and an increase in NH temperature for (a) Northwest, (b) Upper Midwest, (c) Northern Plains, (d) Ohio Valley, (e) Central Plains, (f) Northeast, (g) Southwest, (h) Southeast, and (i) Southern Plains. The heights of the bars represent the median, and the whiskers represent the interquartile range of sensitivity values of all points in each climate region. Statistically significant predictors at $5 \%$ significance level are marked with an asterisk. The $y$-axis scale varies by panel.

magnitude of changes in drought severity due to changes in AMO, PDO, and NH temperature for each climate region are shown in Table 3. According to Fig. 9, the positive phase of AMO leads to an increase in the severity of droughts in the Great Plains region (Northern, Central, and Southern Plains) and the Ohio Valley (Figs. 9c,d,e,i) and the negative phase of PDO leads to increased severity of droughts in the Southern and Central Great Plains, the Northeast, and the Southwest (Figs. 9e,f,g,i). The results of the sensitivity analysis for a decrease in AMO and an increase in the PDO index are shown in Fig. 10. As can be seen, the results in Fig. 10 are mostly of opposite nature to those in Fig. 9. The negative phase of AMO reduces drought severity in the Great Plains and the Ohio Valley, while the positive phase of PDO reduces drought severity in the Southwest, Northeast, and Central and Southern Plains. These results are consistent with the findings of previous studies (Nigam et al. 1999, 2011; Mantua et al. 1997; Mantua and Hare 2002; McCabe et al. 2004). The sensitivity to NH temperature in the SVM models is negative for most parts of the CONUS except the Southeast and the Southwest. It is interesting to note that NH temperature offsets the drought response to the negative phase of PDO in the Southeast but amplifies the PDO drought response in the Southwest (Figs. 9g,h). 
TABLE 3. Median values of baseline severity and median magnitude of changes in drought severity in the sensitivity analysis for each climate region.

\begin{tabular}{|c|c|c|c|c|c|c|}
\hline & \multirow[b]{2}{*}{ Baseline severity } & \multicolumn{5}{|c|}{ Change in severity } \\
\hline & & $\operatorname{AMO}(+)$ & $\operatorname{AMO}(-)$ & $\mathrm{PDO}(+)$ & $\operatorname{PDO}(-)$ & $\mathrm{NH}$ temp $(+)$ \\
\hline Northwest United States & 14.1 & 0.0 & -0.8 & 0.7 & -1.3 & -1.0 \\
\hline Upper Midwest & 13.3 & -0.3 & 0.4 & 0.4 & -1.3 & -1.7 \\
\hline Northern Plains & 14.6 & 1.2 & -1.5 & 0.4 & -1.0 & -1.2 \\
\hline Ohio Valley & 15.7 & 2.4 & -2.4 & 0.5 & -0.5 & -2.8 \\
\hline Central Plains & 16.4 & 3.4 & -1.6 & -3.3 & 5.1 & -1.5 \\
\hline Northeast & 16.2 & -1.6 & -0.2 & -2.8 & 2.6 & -1.9 \\
\hline Southwest & 11.8 & 0.5 & -0.2 & -0.9 & 0.9 & 3.3 \\
\hline Southeast & 11.9 & 0.0 & 0.4 & 0.6 & -1.0 & 1.8 \\
\hline Southern Plains & 12.5 & 1.1 & -0.5 & -0.8 & 1.9 & -1.4 \\
\hline
\end{tabular}

To determine the dominant driver of droughts for each region, we compare the absolute sensitivity values with respect to different predictors using the one-sided WMW rank test at $5 \%$ significance level. A predictor is identified as the dominant driver only if its sensitivity values are found to be significantly higher than the other two predictors. The results of the test are shown in Table 4. In the Central Plains, we find that the influence of both the positive and negative phase of PDO is the strongest among the three predictors, suggesting that internal variability has had the dominant influence on the decadal changes in drought severity in this region. In the Southern Plains too, we find that the negative phase of PDO has the highest sensitivity value but the impact of the positive phase of PDO is weaker than that of the negative phase. However, in the Southeast and the Southwest, the sensitivity values with respect to $\mathrm{NH}$ temperature are significantly larger than those of AMO and PDO, indicating that significant long-term changes in drought severity have occurred in these regions, which cannot be explained by the decadal internal variability in the climate. In other regions including the Northwest, Northeast, Northern Plains, Ohio Valley, and Upper Midwest, the sensitivity values with respect to internal variability and $\mathrm{NH}$ temperature are comparable in magnitude and hence no single driver could be identified as the dominant driver for these regions. The results in Table 4 are largely consistent with the PCA, which found AMO and PDO explain roughly the same portion of variance.

\section{d. Physical mechanisms affecting decadal changes in droughts}

The physical mechanisms by which AMO and PDO influence droughts in the CONUS are well studied (Schubert et al. 2004; Mo et al. 2009; Schubert et al. 2009; Ha. Wang et al. 2010; Seager and Hoerling 2014; Hu and Huang 2009; Burgman and Jang 2015; Newman et al.
2016), but the sensitivity values found to be associated with $\mathrm{NH}$ temperature require physical explanation. For the regions in the northern CONUS, which include the Northwest, the Northern Plains, and the Upper Midwest regions, we find a negative sensitivity to $\mathrm{NH}$ temperature, indicating a long-term decline in drought severity (Figs. 9a-c) in these regions. An increasing trend in precipitation was identified by Groisman et al. (2004) in these regions during the twentieth century. This increasing trend was shown to be associated with the earlier melting of snow in the spring season because of increasing temperatures, which in turn leads to increased formation of cumulonimbus clouds and increased summer precipitation (Groisman et al. 2004). Studies using CMIP5 GCM models also project a decrease in droughts in the northern parts of CONUS due to increased precipitation under global warming (Ahmadalipour et al. 2017; Martin 2018). We also identify a negative sensitivity to $\mathrm{NH}$ temperature in the Ohio Valley, Southern Plains, and Central Plains (Figs. 9d,e,i). Groisman et al. (2004) also found an increasing trend in precipitation in these regions in the twentieth century. This increasing trend was shown to be a result of warming temperatures and the associated increase in the moisture content observed in the atmosphere due to the increase in the moisture holding capacity of the atmosphere (Trenberth et al. 2005), which has been contributing to increased precipitation in these regions. While the negative sensitivity to global warming in Southern and Central Plains in the SVM models is consistent with other observation-based studies (Groisman et al. 2004; Trenberth et al. 2005), GCM models project decrease in precipitation in these regions under future global warming (Ahmadalipour et al. 2017; Martin 2018). The reason for this difference could be that these GCM-based studies have focused on projections in the period toward the end of the twenty-first century, during which the physical mechanisms for precipitation in these regions could be different from 
(a) Northwest US

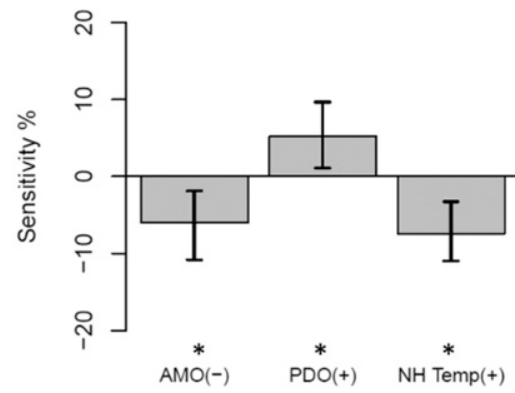

(d) Ohio Valley

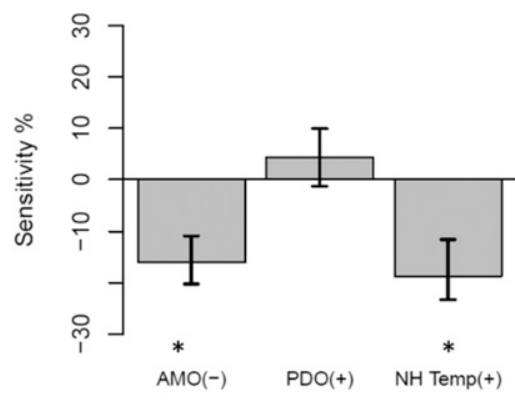

(g) Southwest US

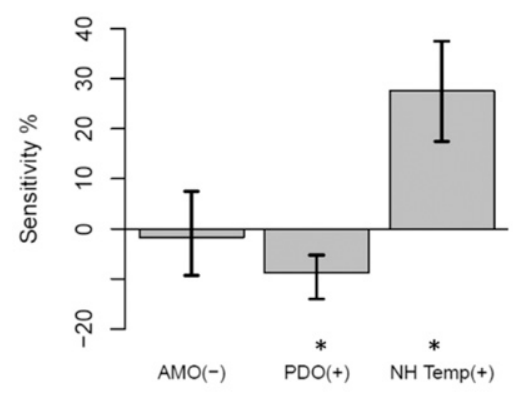

(b) Upper Midwest

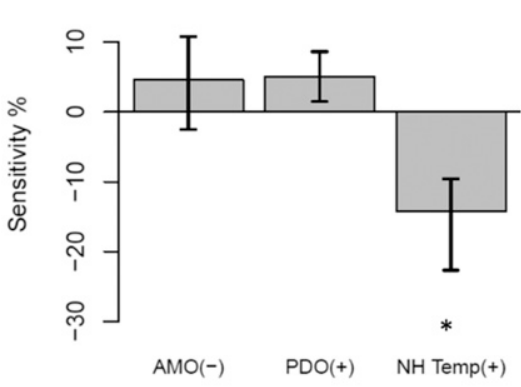

(e) Central Plains

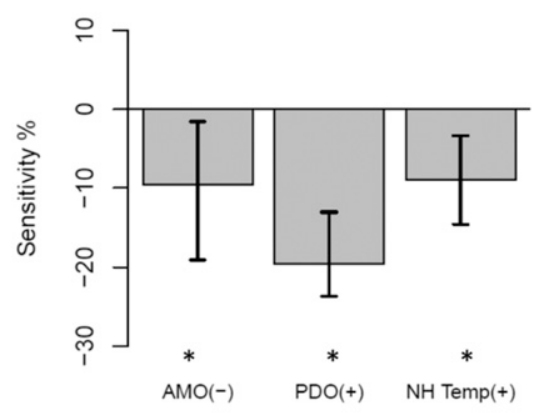

(h) Southeast US

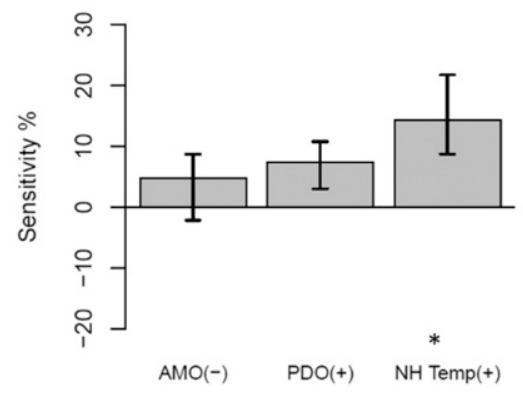

(c) Northern Plains

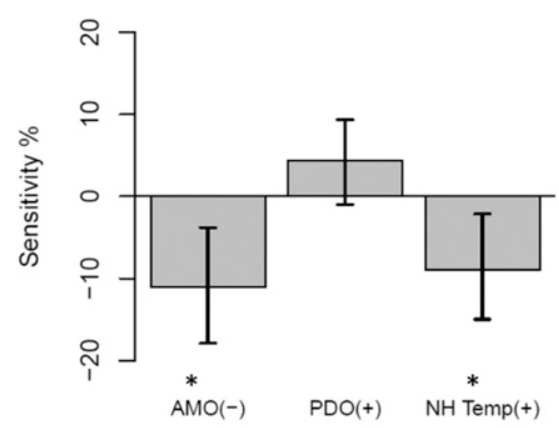

(f) Northeast US

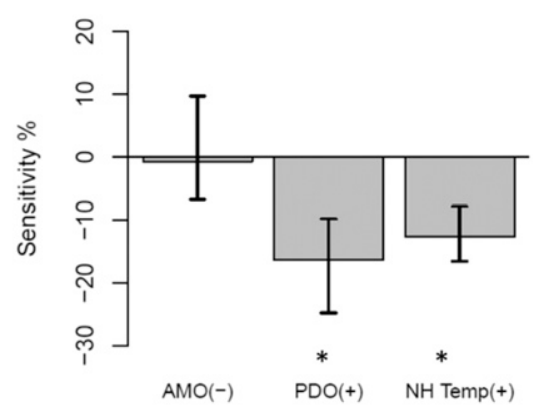

(i) Southern Plains

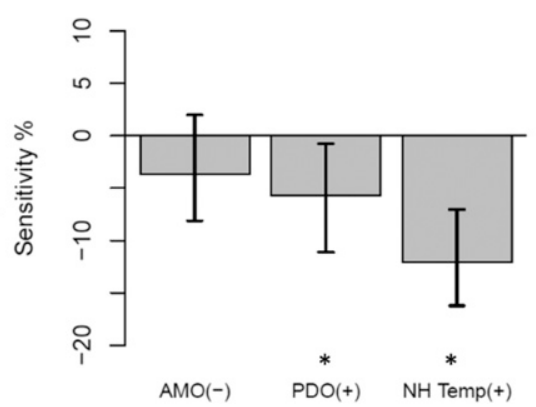

FIG. 10. As in Fig. 9, but for percentage change in the magnitude of the S95 drought severity due to a decrease in AMO, an increase in $\mathrm{PDO}$, and an increase in NH temperature. The $y$-axis scale varies by panel.

those in the present and near future, which is the period of interest for our study.

The Northeast and the Southwest show opposite sensitivity to NH temperature (Figs. 9f,g). These opposite changes in drought severity are likely caused by the recent intensification of the dipole circulation pattern over the United States, which is associated with the formation of an anomalous midtropospheric high pressure ridge over the western United States and a low pressure trough over the eastern United States (Singh et al. 2016) and leads to droughts in the Southwest but increased precipitation in the Northeast. Recent studies have attributed the intensification of the dipole pattern in recent decades to the increased greenhouse gas concentration in the atmosphere (Singh et al. 2016; Wang et al. 2014; Yoon et al. 2015). Studies using GCM models also project an increase in droughts in the Southwest in the future due to global warming (Seager et al. 2007; Seager and Vecchi 2010; Ahmadalipour et al. 2017; Martin 2018). We also find a positive sensitivity to NH temperature for the Southeast (Fig. 9h). Previous studies have reported an increasing trend in droughts in this region in the second half of the twentieth century due to the increasing summer precipitation variability $(\mathrm{Hu}$. Wang et al. 2010). This increasing variability in summer precipitation has been shown to be caused by the westward movement of the North Atlantic subtropical high (NASH) in the recent decades ( $\mathrm{Li}$ et al. 2011). NASH brings warm and humid air from the tropical Atlantic, which leads to large-scale summer precipitation in the 
TABLE 4. Dominant driver of changes in decadal drought severity for each climate region identified using a one-sided WMW test at $5 \%$ significance level.

\begin{tabular}{lc}
\hline Climate region & Dominant driver \\
\hline Northwest & - \\
Upper Midwest & - \\
Northern Plains & - \\
Ohio Valley & - \\
Central Plains & PDO (both phases) \\
Northeast & - \\
Southwest & NH temp \\
Southeast & NH temp \\
Southern Plains & PDO (negative phase) \\
\hline
\end{tabular}

Southeast. However, due to the westward movement of $\mathrm{NASH}$, this moisture is supplied to the Midwest region, leading to droughts in the Southeast. This westward movement of NASH has been attributed to the anthropogenic warming caused by greenhouse gases $(\mathrm{Li}$ et al. 2012). Studies using GCM models project a longterm wetting trend over the Southeast (Ferguson et al. 2018), but with increased variability of precipitation, which is expected to cause more droughts in this region. The variability of rainfall in the Southeast is strongly influenced by NASH. The GCM models which are able to capture the spatial and temporal patterns of NASH project an increase in drought risk for the Southeast in the future due to the intensification of NASH under global warming (Li et al. 2013; Zhu and Stan 2015; Ryu and Hayhoe 2017; Ryu et al. 2018).

The sensitivity values associated with $\mathrm{NH}$ temperature as found in our study, along with the results of these previous studies suggest that these changes are most likely caused by global warming, though the physical mechanisms vary from region to region. Furthermore, the influences of internal variability and global warming on drought severity are described more in the following section, which provide the basis for the assessment of drought severity in the short-term future (10-30 years) in different regions of the CONUS.

\section{e. Drought severity in the near future}

The relationship between droughts and their drivers can be used for estimating the expected regional drought severity in the near future (future decade). Global warming has contributed to increased precipitation in the Midwest, the Great Plains, and the Northwest through increased evaporation and moisture holding capacity of the atmosphere (Groisman et al. 2004; Trenberth et al. 2005). As the atmosphere continues to warm, this effect is likely to intensify (Trenberth et al. 2003), and then contribute toward further increase in precipitation in these regions (IPCC 2014). However, the future drought severity in these regions will be decided by the joint influence of internal variability and global warming. If PDO remains in the negative phase, the Upper Midwest and the Northwest are expected to experience reduced drought severity in the near future, as both internal variability and global warming are likely to contribute toward higher precipitation in these regions (Figs. 9a,b), although, this reduction in drought severity would be smaller if the PDO changes to its positive phase (Figs. 10a,b). The Ohio Valley and the Northern Plains are expected to face increased drought severity due to the positive phase of AMO, but this positive impact of AMO may be weakened by the influence of global warming (Figs. 9c,d). However, if AMO shifts to its negative phase, both these regions could experience a decrease in drought severity (Figs. 10c,d). Similarly, in the Northeast, the impact of the negative phase of PDO, which leads to increased drought severity in this region, may be reduced due to the influence of global warming (Figs. 9f), but a positive phase shift of PDO could lead to reduction in drought severity in this region (Fig. 10f). In the Southern Plains, the positive phase of AMO and the negative phase of PDO are both likely to contribute to increased drought severity in this region in the near future (Fig. 9i). In fact, the effect of $\mathrm{AMO}$ and PDO is already evident in the increase in drought severity observed in this region starting from the late 1990s (Fig. 5i). However, a negative phase shift of AMO or a positive phase shift of PDO in the future could weaken this pattern of increasing drought severity in the Southern Plains (Fig. 10i).

Global warming is the dominant driver of the decadal changes in drought severity in the Southwest and the Southeast (Figs. 9g,h). The study by Wang et al. (2014) has shown that the amplitude of the dipole circulation pattern over the United States has increased in the last few decades. They have attributed the intensification of the dipole pattern to the greenhouse gas induced warming. They project that the continued warming of the atmosphere under the influence of greenhouse gases in the future is expected to further intensify the formation of the dipole circulation pattern over the CONUS, which is likely to cause more droughts in the Southwest and less droughts in the Northeast United States. Similarly, studies using climate models show that increased warming due to greenhouse gases is likely to contribute to further westward movement of NASH in the future (Li et al. 2012). Climate models suggest that this westward movement of NASH will result in reduced moisture supply to the Southeast, leading to droughts in the region, while it would increase the moisture supply to the Midwest and the Northern Plains through the intensification of the Great Plains low-level jets (GPLLJs; 
TABLE 5. Statistically significant predictors under different time scales of SPI and drought thresholds (shown in parentheses).

\begin{tabular}{|c|c|c|c|c|}
\hline \multirow[b]{2}{*}{ Climate region } & \multicolumn{4}{|c|}{ Statistically significant predictors } \\
\hline & SPI3 $(-1)$ & SPI6 $(-1)$ & SPI12 $(-1)$ & SPI3 $(-0.5)$ \\
\hline Northwest & PDO, NH temp & $\mathrm{AMO}, \mathrm{PDO}, \mathrm{NH}$ temp & $\mathrm{PDO}, \mathrm{NH}$ temp & PDO, NH temp \\
\hline Upper Midwest & PDO, NH temp & $\mathrm{PDO}, \mathrm{NH}$ temp & PDO, NH temp & PDO, NH temp \\
\hline Northern Plains & AMO, PDO, NH temp & $\mathrm{AMO}, \mathrm{NH}$ temp & AMO, PDO, NH temp & AMO, PDO, NH temp \\
\hline Ohio Valley & AMO, PDO, NH temp & $\mathrm{AMO}, \mathrm{NH}$ temp & $\mathrm{AMO}, \mathrm{NH}$ temp & AMO, PDO, NH temp \\
\hline Central Plains & $\mathrm{AMO}, \mathrm{PDO}, \mathrm{NH}$ temp & $\mathrm{AMO}, \mathrm{PDO}, \mathrm{NH}$ temp & AMO, PDO, NH temp & AMO, PDO, NH temp \\
\hline Northeast & AMO, PDO, NH temp & $\mathrm{AMO}, \mathrm{PDO}, \mathrm{NH}$ temp & $\mathrm{AMO}, \mathrm{PDO}, \mathrm{NH}$ temp & AMO, PDO, NH temp \\
\hline Southwest & $\mathrm{PDO}, \mathrm{NH}$ temp & PDO, NH temp & $\mathrm{PDO}, \mathrm{NH}$ temp & PDO NH temp \\
\hline Southeast & NH temp & $\mathrm{NH}$ temp & NH temp & NH temp \\
\hline Southern Plains & $\mathrm{AMO}, \mathrm{PDO}, \mathrm{NH}$ temp & PDO, NH temp & PDO, NH temp & AMO, PDO, NH temp \\
\hline
\end{tabular}

Cook et al. 2008). Thus, both the Southwest and the Southeast will likely be exposed to increased drought severity in the near future.

\section{Discussion}

\section{a. Uncertainty analysis}

The methodology used in this study involves the selection of different parameters such as the time scale of SPI calculation, the size of the moving windows, and the threshold used for defining droughts. That is why, it is important to explore if the results are sensitive to the changes in these parameters. The length of the moving window was chosen to be 30 years because the highest correlation between the principal components of the S95 drought severity time series and the moving averages of $\mathrm{AMO}, \mathrm{PDO}$, and $\mathrm{NH}$ temperature was found for the 30 -yr window (Table 2). We also repeated the analysis for different time scales of SPI (6 and 12 months) and for a different drought threshold $(-0.5)$. The results of the analyses are shown in the supplemental material (Figs. S2-S4). The comparison of the statistically significant predictors identified in each of these cases is shown in Table 5. We find that the results in each of these cases were quite similar to those in Fig. 9 except in a few cases. For example, for the Northwest, AMO showed statistically significant influence only under SPI6 but insignificant influence when SPI3 or SPI12 was used. Similarly, PDO showed statistically significant influence in Ohio Valley under SPI3 but insignificant influence for SPI6 and SPI12 droughts. However, most of the drivers identified in section $3 \mathrm{c}$ did not change significantly with the changes in these parameters, probably because the time scale of analysis of the changes in drought severity in this study, which is 30 years, is much larger than the time scale of drought events. The multidecadal changes in precipitation have a significant influence on the drought events at different time scales and different threshold levels. Thus, using different time scales for SPI calculation or different thresholds for defining droughts leads to the identification of similar change patterns in drought severity at the $30-\mathrm{yr}$ time scale.

\section{b. Other factors affecting droughts}

In this study, we have shown that the oscillations in the Atlantic and Pacific SSTs have had a strong influence on the decadal changes in drought severity in the CONUS in the last 115 years. However, there are other factors that can influence the severity of drought events. Some previous studies have used climate models to show that mega droughts, which spanned multiple decades in the preindustrial period, can be generated by atmospheric variability, which is stochastic in nature (Coats et al. 2013; Stevenson et al. 2015). However, the SSTs have been shown to be the dominant forcing of major drought events in the nineteenth and twentieth century (Schubert et al. 2004; Seager et al. 2005; Herweijer et al. 2006). There have been some recent studies which suggest that the oceanic controls on droughts in the CONUS have been decreasing in the last few decades, whereas the atmospheric controls on droughts have been increasing (Kam et al. 2014a; Seager et al. 2014). For example, it has been shown that there was very little role of SSTs in the recent Central Plains and Midwest droughts of 2012 (Kam et al. 2014b; Hoerling et al. 2014). Nevertheless, the observed ongoing patterns at the decadal scale and their strong relationships with SSTs in the last century are not expected to change drastically in the near future, which thus provides valuable information about the drought risk, at least in the near future.

Further, it is important to note that there is a difference between the factors that influence droughts at the event scale from those that affect decadal-scale variability of drought risk. The severity of a drought event can be influenced by land surface processes such as soil moisture feedback, temperature feedback through 
sensible heat flux and transpiration from vegetation. Seasonality can also have a significant influence on droughts as the impacts of AMO and PDO varies by seasons (Nigam et al. 2011; Newman et al. 2016). However, the focus of this study was not on understanding the factors affecting the severity of individual drought events, but to understand the relative changes in seasonal drought severity at the decadal scale, for which AMO, PDO, and global warming are considered the most relevant factors.

\section{Conclusions}

We used a statistical approach to delineate the impacts of internal variability and global warming on droughts in different parts of the CONUS at the decadal scale. We found that the internal variability, represented by AMO and PDO, has had a strong influence on the decadal changes in drought severity in the Great Plains region whereas the Southeast and the Southwest show a significant influence of global warming in the last 115 years.

In the future decade, both internal variability and global warming could contribute to reduced drought severity in the Upper Midwest and the Northwest if PDO remains in its negative phase. Global warming is expected to offset the increase in drought severity in the Northeast and Central Plains due to the negative phase of PDO and in the Ohio Valley and the Northern Plains due to the positive phase of AMO. However, a phase shift of AMO or PDO in the near future could decrease the drought severity in these regions. The Southern Plains are likely to be exposed to increased drought severity if AMO remains in its positive phase and PDO in its negative phase, whereas the Southeast and the Southwest are expected to face increased drought severity due to the influence of global warming. The estimation of drought severity in the short-term future based on the analysis of temporal patterns in the past and the likely changes in the drivers of droughts, as presented in this study, suggests the need for different strategies for regional drought risk management in different parts of the CONUS. Particular attention should be given to Southern Plains, Southeast, and Southwest, which are likely to be exposed to increased drought risk in the future.

Acknowledgments. We are grateful for the financial support for this study by the Institute for Sustainability, Energy and Environment (iSEE), University of Illinois Urbana-Champaign. The study uses the Climate Research Unit monthly rainfall dataset (CRU TS3.24) that has a $0.5^{\circ}$ spatial resolution and covers the period $1901-$ 2015. The monthly time series of AMO was obtained from the National Oceanic and Atmospheric Administration (NOAA) website (https://www.esrl.noaa.gov/ $\mathrm{psd} /$ data/timeseries/AMO), the monthly time series of PDO was also obtained from the NOAA website (https://www.ncdc.noaa.gov/teleconnections/pdo), and the $\mathrm{NH}$ average temperature data were taken from the CRU dataset (www.cru.uea.ac.uk/cru/data/temperature). SVM was implemented using the e1071 package in R (Meyer et al. 2017). We thank the two anonymous reviewers, whose detailed comments and suggestions have significantly helped in improving the quality of the manuscript.

\section{REFERENCES}

Abatzoglou, J. T., and D. E. Rupp, 2017: Evaluating climate model simulations of drought for the northwestern United States. Int. J. Climatol., 37, 910-920, https://doi.org/10.1002/joc.5046.

Ahmadalipour, A., H. Moradkhani, and M. Svoboda, 2017: Centennial drought outlook over the CONUS using NASA-NEX downscaled climate ensemble. Int. J. Climatol., 37, 2477-2491, https://doi.org/10.1002/joc. 4859.

Ault, T. R., J. E. Cole, and S. St. George, 2012: The amplitude of decadal to multidecadal variability in precipitation simulated by state-of-the-art climate models. Geophys. Res. Lett., 39, L21705, https://doi.org/10.1029/2012GL053424.

,,- J. T. Overpeck, G. T. Pederson, S. St. George, B. OttoBliesner, C. A. Woodhouse, and C. Deser, 2013: The continuum of hydroclimate variability in western North America during the last millennium. J. Climate, 26, 5863-5878, https:// doi.org/10.1175/JCLI-D-11-00732.1.

Betts, A. K., 2004: Understanding hydrometeorology using global models. Bull. Amer. Meteor. Soc., 85, 1673-1688, https:// doi.org/10.1175/BAMS-85-11-1673.

Burgman, R. J., and Y. Jang, 2015: Simulated U.S. drought response to interannual and decadal Pacific SST variability. J. Climate, 28, 4688-4705, https://doi.org/10.1175/ JCLI-D-14-00247.1.

Cheung, A. H., M. E. Mann, B. A. Steinman, L. M. Frankcombe, M. H. England, and S. K. Miller, 2017: Comparison of lowfrequency internal climate variability in CMIP5 models and observations. J. Climate, 30, 4763-4776, https://doi.org/10.1175/ JCLI-D-16-0712.1.

Chylek, P., C. Folland, L. Frankcombe, H. Dijkstra, G. Lesins, and M. Dubey, 2012: Greenland ice core evidence for spatial and temporal variability of the Atlantic Multidecadal Oscillation. Geophys. Res. Lett., 39, L09705, https://doi.org/10.1029/ 2012GL051241.

Coats, S., J. E. Smerdon, R. Seager, B. I. Cookand, and J. F. González-Rouco, 2013: Megadroughts in southwestern North America in ECHO-G millennial simulations and their comparison to proxy drought reconstructions. J. Climate, 26, 76357649, https://doi.org/10.1175/JCLI-D-12-00603.1.

Cook, B. I., E. R. Cook, K. J. Anchukaitis, R. Seager, and R. Miller, 2011: Forced and unforced variability of twentieth century North American droughts and pluvials. Climate Dyn., 37, 1097-1110, https://doi.org/10.1007/s00382-010-0897-9.

Cook, K. H., E. K. Vizy, Z. S. Launerand, and C. M. Patricola, 2008: Springtime intensification of the Great Plains low-level jet and Midwest precipitation in GCM simulations of the twenty-first century. J. Climate, 21, 6321-6340, https://doi.org/10.1175/ 2008JCLI2355.1. 
Dai, A., 2013: Increasing drought under global warming in observations and models. Nat. Climate Change, 3, 52-58, https:// doi.org/10.1038/nclimate1633.

Dettinger, M. D., D. S. Battisti, R. D. Garreaud, G. J. McCabe, and C. M. Bitz, 2001: Interhemispheric effects of interannual and decadal ENSO-like climate variations on the Americas. Interhemispheric Climate Linkages, V. Markgraf, Ed., Academic, 1-16, https://doi.org/10.1016/B978-012472670-3/50004-5.

Enfield, D. B., A. M. Mestas-Nunez, and P. J. Trimble, 2001: The Atlantic multidecadal oscillation and its relation to rainfall and river flows in the continental U.S. Geophys. Res. Lett., 28 , 2077-2080, https://doi.org/10.1029/2000GL012745.

Farahmand, A., and A. AghaKouchak, 2015: A generalized framework for deriving nonparametric standardized drought indicators. Adv. Water Resour., 76, 140-145, https://doi.org/10.1016/ j.advwatres.2014.11.012.

Ferguson, C. R., E. F. Wood, and R. K. Vinukollu, 2012: A global intercomparison of modeled and observed land-atmosphere coupling. J. Hydrometeor., 13, 749-784, https://doi.org/10.1175/ JHM-D-11-0119.1.

— - M. Pan, and T. Oki, 2018: The effect of global warming on future water availability: CMIP5 synthesis. Water Resour. Res., 54, 7791-7819, https://doi.org/10.1029/2018WR022792.

Franke, J., D. Frank, C. C. Raible, J. Esper, and S. Bronnimann, 2013: Spectral biases in tree-ring climate proxies. Nat. Climate Change, 3, 360-364, https://doi.org/10.1038/nclimate1816.

Gray, S. T., J. L. Betancourt, C. L. Fastieand, and S. T. Jackson, 2003: Patterns and sources of multidecadal oscillations in drought-sensitive tree-ring records from the central and southern Rocky Mountains. Geophys. Res. Lett., 30, 1316, https://doi.org/10.1029/2002GL016154.

Groisman, P. Ya., R. W. Knight, T. R. Karl, D. R. Easterling, B. Sun, and J. H. Lawrimore, 2004: Contemporary changes of the hydrological cycle over the contiguous United States: Trends derived from in situ observations. J. Hydrometeor., 5, 64-85, https://doi.org/10.1175/1525-7541(2004)005<0064: CCOTHC $>2.0 . \mathrm{CO} ; 2$.

Hastie, T., R. Tibshirani, and J. H. Friedman, 2009: The Elements of Statistical Learning: Data Mining, Inference, and Prediction. 2nd ed. Springer, $745 \mathrm{pp}$.

Herweijer, C., R. Seager, and E. R. Cook, 2006: North American droughts of the mid to late nineteenth century: A history, simulation and implication for mediaeval drought. Holocene, 16, 159-171, https://doi.org/10.1191/0959683606hl917rp.

Hoerling, M., and A. Kumar, 2003: The perfect ocean for drought. Science, 299, 691-694, https://doi.org/10.1126/science.1079053.

— J. Eischeid, J. Perlwitz, X. Quan, T. Zhang, and P. Pegion, 2012: On the increased frequency of Mediterranean drought. J. Climate, 25, 2146-2161, https://doi.org/10.1175/JCLI-D11-00296.1.

,,-- A. Kumar, R. Leung, A. Mariotti, K. Mo, S. Schubert, and R. Seager, 2014: Causes and predictability of the 2012 Great Plains drought. Bull. Amer. Meteor. Soc., 95, 269-282, https://doi.org/10.1175/BAMS-D-13-00055.1.

Hsu, C.-W., C.-C. Chang, and C.-J. Lin, 2004: A practical guide to support vector classification. Tech. Rep., Dept. of Computer Science and Information Engineering, National Taiwan University, $16 \mathrm{pp}$.

Hu, Z., and B. Huang, 2009: Interferential impact of ENSO and PDO on dry and wet conditions in the U.S. Great Plains. J. Climate, 22, 6047-6065, https://doi.org/10.1175/2009JCLI2798.1.

IPCC, 2014: Climate Change 2014: Synthesis Report. IPCC, 151 pp., http://www.ipcc.ch/report/ar5/syr/.
Kam, J., J. Sheffield, and E. F. Wood, 2014a: Changes in drought risk over the contiguous United States (1901-2012): The influence of the Pacific and Atlantic Oceans. Geophys. Res. Lett., 41, 5897-5903, https://doi.org/10.1002/2014GL060973.

_ — - X. Yuan, and E. F. Wood, 2014b: Did a skillful prediction of sea surface temperatures help or hinder forecasting of the 2012 Midwestern US drought? Environ. Res. Lett., 9, 034005, https://doi.org/10.1088/1748-9326/9/3/034005.

Karl, T. R., and W. J. Koss, 1984: Regional and national monthly, seasonal, and annual temperature weighted by area, 18951983. Historical Climatology Series 4-3, National Climatic Data Center, 38 pp., https://repository.library.noaa.gov/view/ noaa/10238.

Lapp, S., J. St. Jacques, E. Barrow, and D. Sauchyn, 2012: GCM projections for the Pacific Decadal Oscillation under greenhouse forcing for the early 21 st century. Int. J. Climatol., 32, 1423-1442, https://doi.org/10.1002/joc.2364.

Li, L., W. Li, and Y. Kushnir, 2012: Variation of the North Atlantic subtropical high western ridge and its implication to southeastern US summer precipitation. Climate Dyn., 39, 14011412, https://doi.org/10.1007/s00382-011-1214-y.

,-- , and Y. Deng, 2013: Summer rainfall variability over the southeastern United States and its intensification in the 21st century as assessed by CMIP5 models. J. Geophys. Res. Atmos., 118, 340-354, https://doi.org/10.1002/jgrd.50136.

Li, W., L. Li, R. Fu, Y. Deng, and H. Wang, 2011: Changes to the North Atlantic subtropical high and its role in the intensification of summer rainfall variability in the southeastern United States. J. Climate, 24, 1499-1506, https://doi.org/ 10.1175/2010JCLI3829.1.

Mantua, N. J., and S. R. Hare, 2002: The Pacific decadal oscillation. J. Oceanogr., 58, 35-44, https://doi.org/10.1023/A:1015820616384.

- — - Y. Zhang, J. Wallace, and R. Francis, 1997: A Pacific interdecadal climate oscillation with impacts on salmon production. Bull. Amer. Meteor. Soc., 78, 1069-1079, https://doi.org/ 10.1175/1520-0477(1997)078<1069:APICOW>2.0.CO;2.

Martin, E. R., 2018: Future projections of global pluvial and drought event characteristics. Geophys. Res. Lett., 45, 11913 11 920, https://doi.org/10.1029/2018GL079807.

McCabe, G. J., and M. D. Dettinger, 1999: Decadal variations in the strength of ENSO teleconnections with precipitation in the western United States. Int. J. Climatol., 19, 1399-1410, https://doi.org/10.1002/(SICI)1097-0088(19991115)19:13<1399:: AID-JOC457>3.0.CO;2-A.

, M. A. Palecki, and J. L. Betancourt, 2004: Pacific and Atlantic Ocean influences on multidecadal drought frequency in the United States. Proc. Natl. Acad. Sci. USA, 101, 4136-4141, https://doi.org/10.1073/pnas.0306738101.

McKee, T. B., N. J. Doesken, and J. Kleist, 1993: The relationship of drought frequency and duration to time scale. Preprints, Eighth Conf. on Applied Climatology, Anaheim, CA, Amer. Meteor. Soc., 179-184.

Meyer, D., E. Dimitriadou, K. Hornik, A. Weingessel and F. Leisch, 2017: e1071: Misc functions of the department of statistics, probability theory group (formerly: E1071), TU Wien, version 1.6-8. R package, https://cran.r-project.org/web/ packages/e1071/index.html.

Mo, K. C., J. Schemm, and S. Yoo, 2009: Influence of ENSO and the Atlantic multidecadal oscillation on drought over the United States. J. Climate, 22, 5962-5982, https://doi.org/10.1175/ 2009JCLI2966.1.

Moon, H., L. Gudmundssonand, and S. I. Seneviratne, 2018: Drought persistence errors in global climate models. 
J. Geophys. Res. Atmos., 123, 3483-3496, https://doi.org/ 10.1002/2017JD027577.

Newman, M., and Coauthors, 2016: The Pacific decadal oscillation, revisited. J. Climate, 29, 4399-4427, https://doi.org/10.1175/ JCLI-D-15-0508.1.

Nigam, S., M. Barlow, and E. H. Berbery, 1999: Analysis links Pacific decadal variability to drought and streamflow in United States. Eos, Trans. Amer. Geophys. Union, 80, 621625, https://doi.org/10.1029/99EO00412.

_ B. Buan, and A. Ruiz-Barradas, 2011: Key role of the Atlantic multidecadal oscillation in 20th century drought and wet periods over the Great Plains. Geophys. Res. Lett., 38, L16713, https://doi.org/10.1029/2011GL048650.

Polade, S. D., A. Gershunov, D. R. Cayan, M. D. Dettinger, and D. W. Pierce, 2017: Precipitation in a warming world: Assessing projected hydro-climate changes in California and other Mediterranean climate regions. Sci. Rep., 7, 10 783, https:// doi.org/10.1038/s41598-017-11285-y.

Roberts, D. R., and Coauthors, 2017: Cross-validation strategies for data with temporal, spatial, hierarchical, or phylogenetic structure. Ecography, 40, 913-929, https://doi.org/10.1111/ecog.02881.

Ryu, J.-H., and K. Hayhoe, 2017: Observed and CMIP5 modeled influence of large-scale circulation on summer precipitation and drought in the south-central United States. Climate Dyn., 49, 4293-4310, https://doi.org/10.1007/s00382-017-3534-z.

,-- , and S.-L. Kang, 2018: Projected changes in summertime circulation patterns imply increased drought risk for the southcentral United States. Geophys. Res. Lett., 45, 11 447-11455, https://doi.org/10.1029/2018GL080593.

Schubert, S. D., M. J. Suarez, P. J. Pegion, R. D. Koster, and J. T. Bacmeister, 2004: Causes of long-term drought in the U.S. Great Plains. J. Climate, 17, 485-503, https://doi.org/10.1175/ 1520-0442(2004)017<0485:COLDIT > 2.0.CO;2.

_- , and Coauthors, 2009: A U.S. CLIVAR project to assess and compare the responses of global climate models to drought-related SST forcing patterns: Overview and results. J. Climate, 22, 5251-5527, https://doi.org/10.1175/ 2009JCLI3060.1.

Seager, R., and G. A. Vecchi, 2010: Greenhouse warming and the 21st century hydroclimate of southwestern North America. Proc. Natl. Acad. Sci. USA, 107, 21 277-21 282, https://doi.org/ 10.1073/pnas.0910856107.

, and M. Hoerling, 2014: Atmosphere and ocean origins of North American droughts. J. Climate, 27, 4581-4606, https:// doi.org/10.1175/JCLI-D-13-00329.1.

—, Y. Kushnir, C. Herweijer, N. Naik, and J. Velez, 2005: Modeling of tropical forcing of persistent droughts and pluvials over western North America: 1856-2000. J. Climate, 18, 4065-4088, https://doi.org/10.1175/JCLI3522.1.

- , and Coauthors, 2007: Model projections on an imminent transition to a more arid climate in southwestern North America Science, 316, 1181-1184, https://doi.org/10.1126/science.1139601.

— L. Loddard, J. Nakamura, N. Henderson, and D. E. Lee, 2014: Dynamical causes of the 2010/11 Texas-northern Mexico drought. J. Hydrometeor., 15, 39-68, https://doi.org/10.1175/ JHM-D-13-024.1.

Sheffield, J., and Coauthors, 2013: North American climate in CMIP5 experiments. Part II: Evaluation of historical simulations of intraseasonal to decadal variability. J. Climate, 26, 9247-9290, https://doi.org/10.1175/JCLI-D-12-00593.1.

Singh, D., D. L. Swain, J. S. Mankin, D. E. Horton, L. N. Thomas, B. Rajaratnam, and N. S. Diffenbaugh, 2016: Recent amplification of the North American winter temperature dipole. J. Geophys. Res. Atmos., 121, 99119928, https://doi.org/10.1002/2016JD025116.

Stagge, J. H., L. M. Tallaksen, L. Gudmundsson, A. F. van Loon, and K. Stahl, 2015: Candidate distributions for climatological drought indices (SPI and SPEI). Int. J. Climatol., 35, 40274040, https://doi.org/10.1002/joc.4267.

Stevenson, S., A. Timmermann, Y. Chikamoto, S. Langford, and P. DiNezio, 2015: Stochastically generated North American megadroughts. J. Climate, 28, 1865-1880, https://doi.org/10.1175/ JCLI-D-13-00689.1.

Svensson, C., J. Hannaford, and I. Prosdocimi, 2017: Statistical distributions for monthly aggregations of precipitation and streamflow in drought indicator applications. Water Resour. Res., 53, 999-1018, https://doi.org/10.1002/2016WR019276.

Trenberth, K. E., A. Dai, R. M. Rasmussen, and D. B. Parsons, 2003: The changing character of precipitation. Bull. Amer. Meteor. Soc., 84, 1205-1217, https://doi.org/10.1175/BAMS-84-9-1205.

- J. T. Fasullo, and L. Smith, 2005: Trends and variability in column-integrated atmospheric water vapour. Climate Dyn., 24, 741-758, https://doi.org/10.1007/s00382-005-0017-4.

Vapnik, V., 1995: The Nature of Statistical Learning Theory. Springer, $314 \mathrm{pp}$.

Wang, Ha., S. Schubert, M. Suarez, and R. Koster, 2010: The physical mechanisms by which the leading patterns of SST variability impact U.S. precipitation. J. Climate, 23, 18151836, https://doi.org/10.1175/2009JCLI3188.1.

Wang, Hu., R. Fu, A. Kumar, and W. Li, 2010: Intensification of summer rainfall variability in the southeastern United States during recent decades. J. Hydrometeor., 11, 1007-1018, https:// doi.org/10.1175/2010JHM1229.1.

Wang, J., and C. Li, 2017: Low-frequency variability and possible changes in the North Pacific simulated by CMIP5 models. J. Meteor. Soc. Japan, 95, 199-211, https://doi.org/10.2151/jmsj.2017-011.

Wang, S.-Y., L. Hipps, R. R. Gillies, and J. H. Yoon, 2014: Probable causes of the abnormal ridge accompanying the 2013-2014 California drought: ENSO precursor and anthropogenic warming footprint. Geophys. Res. Lett., 41, 3220-3226, https:// doi.org/10.1002/2014GL059748.

Wilcoxon, F., 1945: Individual comparisons by ranking methods. Biometrics, 1, 80-83, https://doi.org/10.2307/3001968.

Wilhite, D. A., M. J. Hayes, C. Knutson, and K. H. Smith, 2000: Planning for drought: Moving from crisis to risk management. J. Amer. Water Resour. Assoc., 36, 697-710, https://doi.org/ 10.1111/j.1752-1688.2000.tb04299.x.

World Meteorological Organization, 2006: Drought monitoring and early warning: Concepts, progress and future challenges. WMO Rep. 1006, 24 pp., http://www.wamis.org/agm/pubs/ brochures/WMO1006e.pdf.

Wu, S., Z. Liu, R. Zhang, and T. Delworth, 2011: On the observed relationship between the Pacific decadal oscillation and the Atlantic multi-decadal oscillation. J. Oceanogr., 67, 27-35, https:// doi.org/10.1007/s10872-011-0003-x.

Yoon, J. H., S.-Y. Wang, R. G. Gillies, B. Kravitz, L. Hippsand, and P. J. Rasch, 2015: Increasing water cycle extremes in California in relation to ENSO cycle under global warming. Nat. Commun., 6, 8657, https://doi.org/10.1038/ncomms9657.

Zhang, L., and T. L. Delworth, 2016: Simulated response of the Pacific decadal oscillation to climate change. J. Climate, 29, 5999-6018, https://doi.org/10.1175/JCLI-D-15-0690.1.

Zhu, X., and C. Stan, 2015: Projection of summer precipitation over the southeastern United States in the superparameterized CCSM4. J. Climate, 28, 8052-8066, https://doi.org/10.1175/ JCLI-D-14-00765.1. 